\title{
Geomorfología de cuencas criogénicas de altura en la Sierra de Santa Victoria, provincia de Salta
}

\author{
Geomorphological characterization of high cryogenic basins in the \\ Sierra de Santa Victoria, Salta province
}

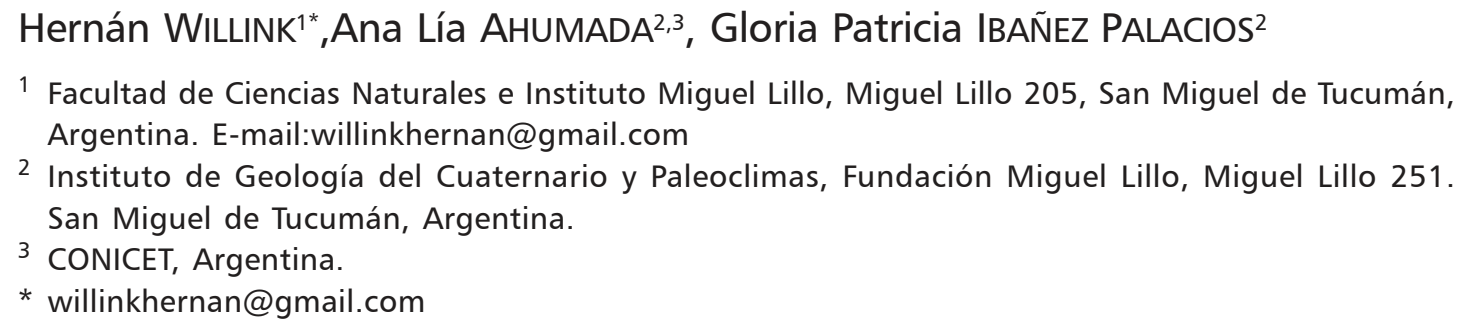

\section{RESUMEN}

Este trabajo tiene como objetivo efectuar el relevamiento, inventario y descripción de las geoformas y procesos periglaciales y glaciales en cuencas criogénicas de altura, en la sierra de Santa Victoria, provincia de Salta. Se identificó una asociación importante de microformas (suelos rastrillados, estructuras porridge, selección vertical) y mesoformas, donde se destacan los glaciares de escombros, que indican condiciones de permafrost de montaña y constituyen recursos hídricos de altura. Estas geoformas representan las expresiones máximas de los ambientes periglaciales. Se confeccionaron mapas temáticos de variables del terreno que tienen relación directa con el desarrollo de los procesos y geoformas criogénicas. Además, se reconocieron fenómenos de deterioro o degradación del permafrost que indican la necesidad de planes de manejo organizados de los recursos ante los posibles riesgos por efecto del calentamiento global.

Palabras clave - Geoformas criogénicas, permafrost de montaña, graciares de escombros, sierra de Santa Victoria.

Ref. bibliográfica: Willink, H.; Ahumada, A. L.; Ibañez Palacios, G. P. 2020. "Geomorfología de cuencas criogénicas de altura en la Sierra de Santa Victoria, provincia de Salta". Acta geológica lilloana 32 (1-2): 4773. Fundación Miguel Lillo, Tucumán, Argentina. D.O.I.: https://doi.org/10.30550/j.agl/2020.32.1-2/3 > Recibido: 17 de julio 2020 - Aceptado: 21 de noviembre 2020. 


\begin{abstract}
"Geomorphological characterization of high cryogenic basins in the Sierra de Santa Victoria, Salta province".- The objective of this research is the survey, inventory, and description of landforms and periglacial and glacial processes in high cryogenic basins in the mountain of Santa Victoria, Salta province. An important association of microforms (raked soils, porridge structures, vertical selection) and mesoforms was identified, where rock glaciers stand out, indicating mountain permafrost conditions and constitute high-altitude water resources. These geoforms represent the maximum expressions of periglacial environments. Thematic maps of terrain variables that are directly related to the development of periglacial processes and landforms were made. In addition, phenomena of permafrost degradation were recognized that show the need of organized management of the resources facing the possible risks of global warming effects.
\end{abstract}

Keywords - Cryogenic landforms, mountain permafrost, rock glaciers, Santa Victoria mountain range.

\title{
INTRODUCCION
}

Este trabajo pretende contribuir al conocimiento de los ambientes criogénicos del norte argentino y al mapeo tanto de permafrost de montaña como de geoformas glaciares, en un sector de la subcuenca del río Iruya perteneciente a la Cuenca Alta del río Bermejo. En esta región, en el ámbito de Cordillera Oriental, la criósfera está representada por la presencia de permafrost andino o de montaña, que se manifiesta con una asociación de mesoformas y geoformas menores, originadas por el congelamiento permanente o estacional del suelo. El permafrost es una condición térmica, los suelos deben permanecer congelados permanentemente por más de dos años para ser llamados como tal (International Permafrost Association, 1994), por lo tanto, su formación, persistencia o desaparición son altamente dependientes del clima.

Las geoformas más destacadas de permafrost de montaña rico en hielo son los glaciares de escombros, identificados como permafrost reptante por sus condiciones de saturación en hielo y movimiento gravitacional (Haeberli, 1985; Barsch, 1996; Trombotto, 2000). En el NOA se encuentran ubicados en alturas desde 4.000 a 4.850 m.s.n.m., acompañados por otras geoformas periglaciales (Ahumada, 2008). En esta región, el permafrost discontinuo ha sido detectado en las cabeceras de ríos principales, a distintas alturas y diferentes condiciones de clima local. Su condición térmica actual estaría en desequilibrio con el modelo climático planteado por Haeberli (1985) para su formación: rangos de precipitación de 400 a $2.500 \mathrm{~mm}$ anuales y de temperatura media anual de $-15^{\circ} \mathrm{C}$ a $-2^{\circ} \mathrm{C}$. Considerando este modelo, los glaciares de escombros en el NOA permanecerían en un equilibrio inestable y ecológicamente resilientes con las condiciones de temperatura y precipitación del clima actual (Ahumada et al., 2006).

La importancia de las distintas geoformas criogénicas es que algunas de ellas actúan como reservas de agua dulce en las regiones continentales y ante la situación 
climática actual se considera muy relevante la realización de dicho mapeo, ya que pondría a disposición de los entes responsables de tomar decisiones, información fundamental para regular y controlar los recursos hídricos de regiones áridas de altura (Ahumada et al., 2005 a, b; Ahumada, 2007; Ahumada et al., 2015; Ahumada et al., 2017).

El objetivo principal de este estudio, es el relevamiento e inventario de las geoformas periglaciales, con la determinación de sus características morfométricas, y una breve descripción de las geoformas glaciales más representativas del sector, como morenas y circos glaciarios. Los datos obtenidos son un aporte al conocimiento de la geomorfología de cuencas criogénicas de alta montaña, en el ámbito de la sierra de Santa Victoria, provincia de Salta. Además, contribuye a la evaluación de las cuencas hídricas de altura y sus reservas de agua dulce, información útil para el manejo de este recurso, el desarrollo sustentable y prevención de riesgos en las cuencas bajas. Aporta información a la significancia hidrológica de la región.

\section{MARCO REGIONAL}

\section{Ubicación}

$\mathrm{El}$ área de estudio, con una superficie aproximada de $5 \mathrm{~km}^{2}$, se encuentra ubicada al noroeste de la provincia de Salta, departamento Santa Victoria, en el flanco occidental de la sierra de Santa Victoria. Se localiza entre los paralelos $22^{\circ} 26^{\prime} 45^{\prime \prime}$ y $22^{\circ} 26 ’ 52^{\prime \prime}$

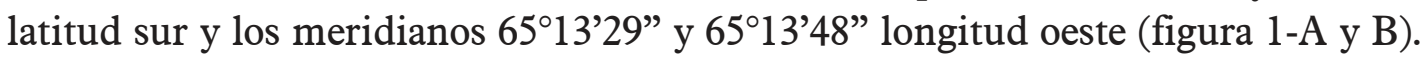

Para acceder a la región desde San Miguel de Tucumán se toma por ruta nacional $\mathrm{N}^{0} 9$ hasta la localidad de La Quiaca, en la provincia de Jujuy, desde aquí se continúa hacia el este por la ruta provincial $\mathrm{N}^{\circ} 5$ hasta el empalme con la ruta provincial $\mathrm{N}^{\mathrm{o}} 67$ que cambia a ruta provincial No 69 hasta el Abra del Cóndor (4.501 m.s.n.m.), desde allí, ya en suelo salteño pasa a ser la ruta provincial $\mathrm{N}^{0} 145$. Desde aquí se transita aproximadamente $10 \mathrm{~km}$ por un camino o huella de montaña hasta llegar a la zona de estudio.

\section{Orografía}

La sierra de Santa Victoria se extiende entre los paralelos $22^{\circ} 08^{\prime}$ y $23^{\circ} 00^{\prime}$ latitud sur (Trópico de Capricornio) y los meridianos $65^{\circ}$ y $65^{\circ} 30^{\prime}$ longitud oeste. Conforma un cordón longitudinal angosto orientado en dirección norte-sur en su tramo septentrional y nornordeste-sursuroeste en su parte austral.

El área de estudio se encuentra sobre la ladera occidental, con alturas que varían entre los 4.200 a 5.000 m.s.n.m.

\section{Hidrografía}

La zona, a gran escala, pertenece a la Cuenca Alta del río Bermejo, esta cuenca Alta o Superior abarca el extremo sureste de Bolivia y el noroeste de Argentina, con alturas que varían desde los 3.600 m.s.n.m a los 5.000 m.s.n.m y una superficie de 13.474 


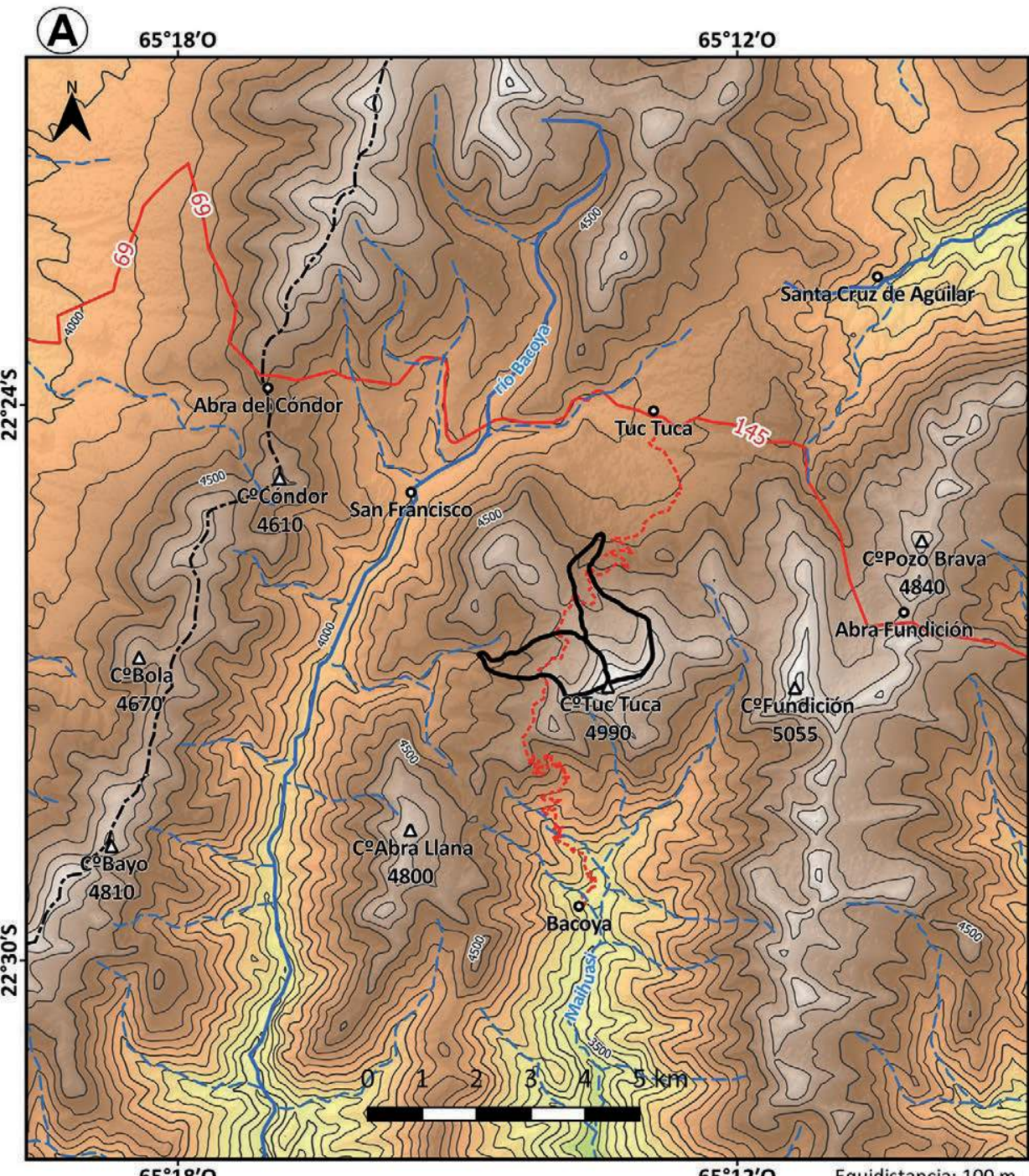

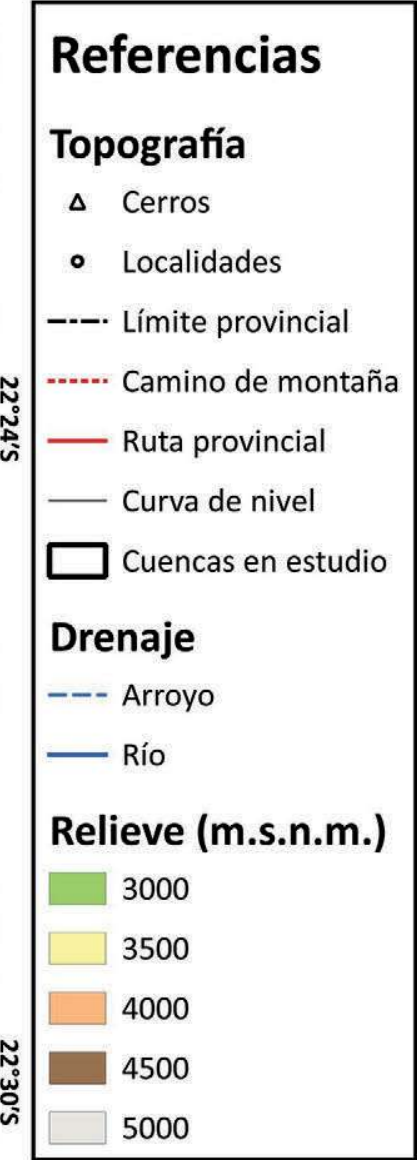

Proyección: UTM Datum: WGS 84 Fuentes: IGN - IDERA - CSI
(B)

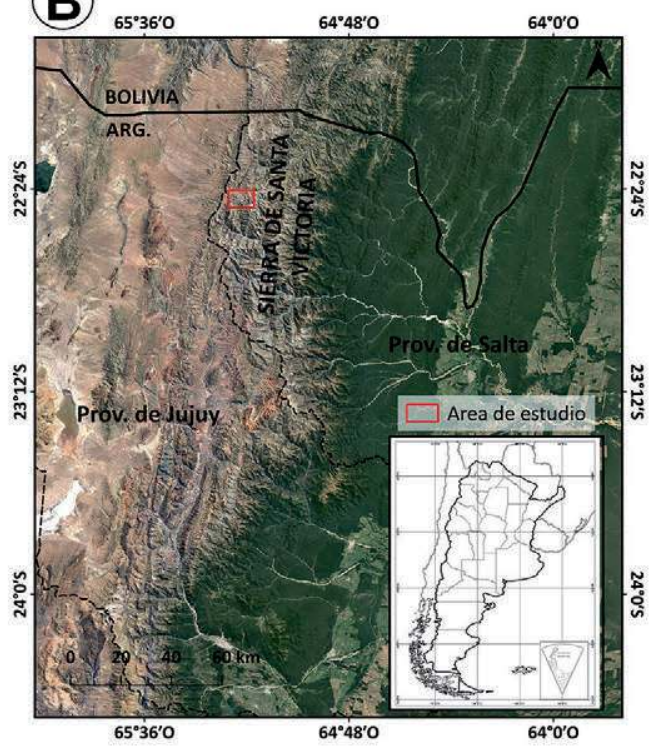

(C)

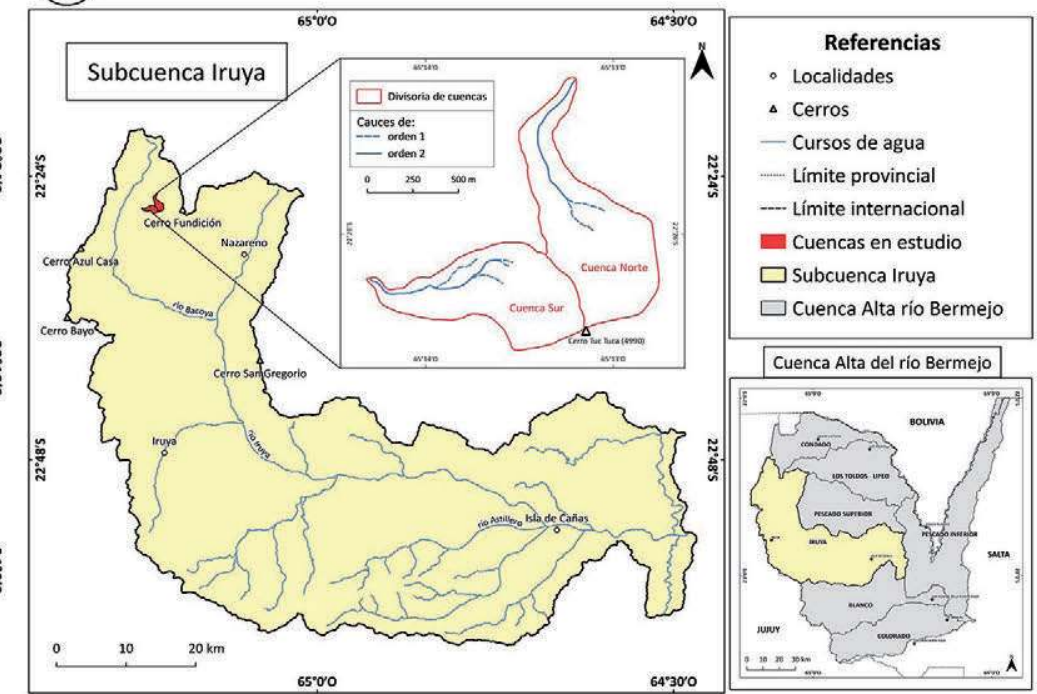

Figura 1. A) Mapa topográfico de la región de estudio. B) Ubicación. C) Localización de cuencas en estudio y detalle de las mismas. 
$\mathrm{km}^{2}$. Esta Cuenca se divide, a su vez, en subcuencas: Condado, Los Toldos - Lipeo, Pescado Superior, Iruya, Blanco, Pescado Inferior - Grande de Tarija y Colorado.

Las cuencas criogénicas en estudio, siguiendo el método de clasificación de Horton (1945), son de segundo orden y aportan sus aguas al río Bacoya, que pertenece a la subcuenca del río Iruya (figura 1-C). En general, la red de drenaje en esta zona está compuesta por cursos temporarios, que aparecen por precipitaciones aisladas, más comúnmente en forma de granizo o nieve, y por el posible aporte de agua de descongelamiento del permafrost, contenido en las distintas geoformas criogénicas.

\section{Clima y vegetación}

Siguiendo la clasificación climática de Köppen (1923) la zona estudiada pertenece al tipo de clima de alta montaña (EB, según su terminología), y de acuerdo a la clasificación de provincias fitogeográficas de Cabrera (1976) la zona corresponde a la provincia alto-andina.

Según datos tomados de la estación meteorológica de La Quiaca y cálculos extrapolados, Ahumada et al. (2014) determinaron una temperatura media anual del aire de $1,9^{\circ} \mathrm{C}$ para los 4.400 m.s.n.m. y $0,3^{\circ} \mathrm{C}$ para los 4.600 m.s.n.m. aproximadamente. Martini et al. (2013) establecen para toda la Cordillera Oriental, en base a la temperatura media anual obtenidas de la estación meteorológica antes mencionada y aplicando un gradiente térmico estándar de disminución de temperatura con el aumento de altura de $-0,7^{\circ} \mathrm{C} / 100 \mathrm{~m}$, que la altura de la isoterma de $0^{\circ} \mathrm{C}$ actual se sitúa a 4.916 m.s.n.m.

Con respecto a las precipitaciones, al igual que en toda esta región del NOA y Andes, se concentran durante la estación estival. Los vientos alisios procedentes del Atlántico, descargan su humedad en las Sierras Subandinas y la Cordillera Oriental de la provincia de Salta con los mayores niveles de precipitación, unos $1.200 \mathrm{~mm}$ en promedio, en alturas inferiores a los 3.000 m.s.n.m. correspondientes a la cuenca baja. Estos vientos al ascender a la región de trabajo, llegan poco cargados de humedad, con alrededor de $390 \mathrm{~mm}$ (Kull et al., 2003). Un gradiente altitudinal de las escasas precipitaciones muestra que son menores a $500 \mathrm{~mm} /$ año por encima de 3.500 m.s.n.m. En los sectores más altos de las serranías la precipitación generalmente se presenta en forma de granizo o nieve (Igarzábal, 1981). Estas condiciones meteorológicas generan fenómenos de congelamiento y descongelamiento diario y estacional. Estos procesos favorecen la permanencia de paisajes periglaciales e imponen severas limitaciones al desarrollo de la vida vegetal. La vegetación preponderante es la de las estepas graminosas y arbustivas, que en general, presentan una alta adaptación a las condiciones xéricas extremas y a la defensa contra el frío y el viento.

La orografía juega un rol primordial en el clima para esta región de altura. Zipprich et al. (2000) y Haselton et al. (2002) opinan que el patrón de circulación atmosférico, que provoca que las laderas orientales de las sierras sean más húmedas, se habría mantenido estable desde el Pleistoceno tardío asociado a la disposición estructural N-S de la sierra. Esto es determinante en la conservación de las características morfocriogénicas del sector (Masaguer, 2009). 
Los suelos pueden ser rocosos y arenosos, sueltos o inmaduros, y en zonas donde se acumula humedad se desarrollan vegas o turberas. Debido al régimen hídrico Arídico y Tórrico, Puchulu y Fernández (2017) establecen que lo suelos más representativos en esta zona de Santa Victoria, pertenecen a los Aridisoles (Paleargides y Cambortides típicos), Entisoles (Torriortentes líticos) y suelos Mólicos (Haplocrioles típicos), que son suelos débilmente desarrollados, formados bajo rigurosas condiciones climáticas, con abundantes detritos rocosos angulares de grava gruesa.

\section{Población}

Exceptuando a poblaciones más desarrolladas como Santa Victoria Oeste, Iruya y Nazareno, los habitantes de la región se distribuyen en pequeños caseríos o rodeos, aprovechando los valles más fértiles, dispersos por los cerros en sitios alejados. Poseen una tradición antigua con valiosas expresiones culturales mestizas e indígenas de los grupos denominados collas. La ganadería y agricultura representan la actividad productiva de la región, tratándose de una economía de subsistencia.

\section{MARCO GEOLÓGICO GENERAL}

La sierra de Santa Victoria constituye la cadena montañosa más septentrional de la provincia geológica de Cordillera Oriental. Esta se encuentra ubicada en el borde este de la Cordillera de los Andes entre los países de Argentina, Bolivia y Perú, posee una forma elongada en sentido norte-sur, extendiéndose desde los $26,3^{\circ} \mathrm{S}$ hasta los $22^{\circ} \mathrm{S}$, y cubriendo una superficie de $48.730 \mathrm{~km}^{2}$.

El estilo estructural marcado por la tectónica neógena, en la Cordillera Oriental, es de fallamiento y plegamiento, representando una comarca elevada que se desplaza hacia el este sobre Sierras Subandinas.

La columna estratigráfica de la región se inicia con un basamento metamórfico de bajo grado constituido por pizarras y grauvacas de edad precámbrica-cámbrica inferior (Escayola et al., 2011) correspondientes a la Formación Puncoviscana, que constituye el núcleo del Cerro Tuc Tuca. Sobre estas rocas y en discontinuidad se apoya una potente secuencia dominantemente cuarcítica de edad cámbrica mediasuperior correspondiente al Grupo Mesón (Turner, 1960), este Grupo representa la ingresión marina más antigua conocida en los Andes Centrales. El Grupo Mesón está compuesto de la base al techo por las Formaciones Lizoite, Campanario y Chalhualmayoc; que constituyen una secuencia silicoclástica litoral-marina somera con notable influencia de corrientes de marea (Sánchez y Salfity, 1999). Sobre las "ortocuarcitas" rosadas del Grupo Mesón se dispone en discordancia el Ordovícico, correspondiente al Grupo Santa Victoria, representado por su unidad más importante la Formación Santa Rosita, constituida principalmente por conglomerados y lutitas. La columna estratigráfica de la región culmina con acumulaciones clásticas del Pleistoceno superior y Holoceno, estos depósitos corresponden a material morénico, los cuales están compuestos por bloques, arenas, limo-arcilla, till de fondo y turbas. Representan depósitos glacifluviales y fluviales y, además, actuales depósitos 
lacustres de pequeñas dimensiones y potencia. También están incluidos los depósitos de criosedimento y permafrost de los glaciares de escombros y talus.

\section{Geomorfología}

A pesar que actualmente impera un ambiente marcado por procesos y geoformas periglaciales, estas regiones presentaron en el pasado condiciones glaciarias, evidenciadas a partir de diferentes rasgos morfológicos como las morenas y circos glaciarios.

El ambiente glacial es previo al desarrollo de las geoformas periglaciales mayores en esta región. Estas geoformas con permafrost se instalan posteriormente y, en algunos casos, en convivencia con eventos glaciares. Los cuales perduran en el tiempo preservando núcleos de hielo, constituyéndose en el reservorio hídrico de la criósfera activa en la zona de trabajo.

Zipprich et al. (2000) encuentran evidencias de ocho generaciones de depósitos morénicos y tres generaciones sucesivas de glaciares de escombros activos y, en base a dataciones de radiocarbono e índices de meteorización en paleosuelos, la edad relativa para los procesos glaciales y periglaciales de la región: las morenas más antiguas datadas son anteriores al Último Máximo Glacial (25 a 13 mil años antes del presente), y los glaciares de escombros más antiguos datan del período Máximo Tardiglacial (13 a 10 mil años antes del presente). Posteriormente, Zech et al. (2009), en base a 10Be y análisis de sedimentos de lagos en el extremo $\mathrm{N}$ de la sierra de Santa Victoria dataron varios eventos glacigénicos desde el Estadío Isotópico 5 al Tardiglacial.

\section{METOdOLOGÍA}

Para la realización de este trabajo se efectuó un primer control de campo donde se reconocieron las distintas geoformas periglaciales, observaciones in situ de procesos de congelamiento estacional y otros procesos menores no visibles en fotografías aéreas e imágenes satelitales. Además, se determinó la actividad de estas geoformas y procesos, se verificaron caídas de rocas en los frentes y estimaciones de la superficie cubierta por vegetación en glaciares de escombros. Las mediciones de las pendientes de los frentes de glaciares de escombros se realizaron con el uso de un clinómetro Suunto, las coordenadas geográficas y altitudes de los glaciares de escombros se determinaron con GPS marca Garmin.

Los mapas y la delimitación de geoformas fueron digitalizadas de forma manual mediante el software libre QGIS versión 3.4.7; como base topográfica se utilizó un Modelo Digital de Elevación (MDE) ALOS PALSAR con resolución espacial de 12,5 m, obtenido de: search.asf.alaska.edu/. El resto de la información cartográfica de base fue obtenida del IGN (Instituto Geográfico Nacional) y de IDERA (Infraestructura de Datos Espaciales de la República Argentina).

El mapeo geomorfológico (escala 1:20.000) se confeccionó sobre la base de imágenes de alta resolución de la plataforma Google Earth, y con el apoyo de imágenes satelitales de adquisición libre como Landsat 8 (sensor OLI, resolución de 30 m) 
y CBERS (sensor HRC, resolución 2,7 m), la selección de estas imágenes se realizó teniendo en cuenta que sean de fechas recientes, sin cobertura de nieve (fechas estivales) y ausencia de nubes. En el reconocimiento y clasificación de los glaciares de escombros y prótalus rampart, al estar compuestos por más de un polígono con una asociación de estas geoformas cuyos límites no están bien definidos, se los delimitó como una sola unidad.

Los mapas de análisis del terreno, confeccionados en el entorno SIG anteriormente mencionado, fueron calculados a partir del MDE. Las variables seleccionadas fueron la orientación y pendiente. Para el primer caso los valores fueron clasificados en 4 clases: norte $\left(315^{\circ}\right.$ a $\left.45^{\circ}\right)$, este $\left(45^{\circ}\right.$ a $\left.135^{\circ}\right)$, sur $\left(135^{\circ}\right.$ a $\left.225^{\circ}\right)$ y oeste $\left(225^{\circ}\right.$ a $315^{\circ}$ ). La pendiente varía de $0^{\circ}$ a $55^{\circ}$ y clasificados en 4 clases.

Para las definiciones de los procesos y geoformas periglaciales y glaciales se utilizó la terminología aceptada internacionalmente, en base a la Guía Terminológica de la Geocriología Sudamericana de Trombotto et al. (2014), que a su vez se sustenta en otros trabajos como "Glossary of Permafrost and Related Ground Ice Terms" (van Everdingen, 2005), "Glossary of Glacier Mass Balance and Related Terms (Glosario de Glaciares)" (Cogley et al., 2011), y el "Illustrated Glossary of Snow and Ice" (Armstrong et al., 1997).

\section{RESULTADOS}

Los resultados obtenidos para las dos cuencas: una Norte y una Sur (figura 2), se dividen en diferentes secciones de acuerdo a los objetivos propuestos, haciendo hincapié en el mapa geomorfológico con el reconocimiento y caracterización de las geoformas periglaciales y glaciales, y un análisis especial para los glaciares de escombros debido a su importancia en estos ambientes. Además, se realizó la interpretación y relación existente entre las geoformas y procesos más importantes con los rasgos y representación de estos en el terreno. Finalmente, una identificación de las formas de degradación presentes de permafrost.

\section{Distribución y caracterización de las geoformas glaciales y periglaciales}

Las cuencas con geoformas criogénicas estudiadas cubren un área total de $4,59 \mathrm{~km}^{2}$, la cuenca norte ocupa una superficie de $2,61 \mathrm{~km}^{2}$ y la sur de $1,98 \mathrm{~km}^{2}$. Las geoformas glaciales y periglaciales inventariadas en las cuencas, cubren una superficie de $4,24 \mathrm{~km}^{2}$ (figura 3), constituyendo el $92,4 \%$ de la superficie total de las cuencas. En total se inventariaron 33 geoformas, reconociéndose 16 en la cuenca norte y 17 en la cuenca sur.

Analizando, en primer lugar, los procesos periglaciales menores (figura 4), característicos en estos ambientes criogénicos, por lo que son importantes de mencionar, pero que no fueron inventariados ni representados cartográficamente por su pequeña escala, podemos señalar los siguientes: 


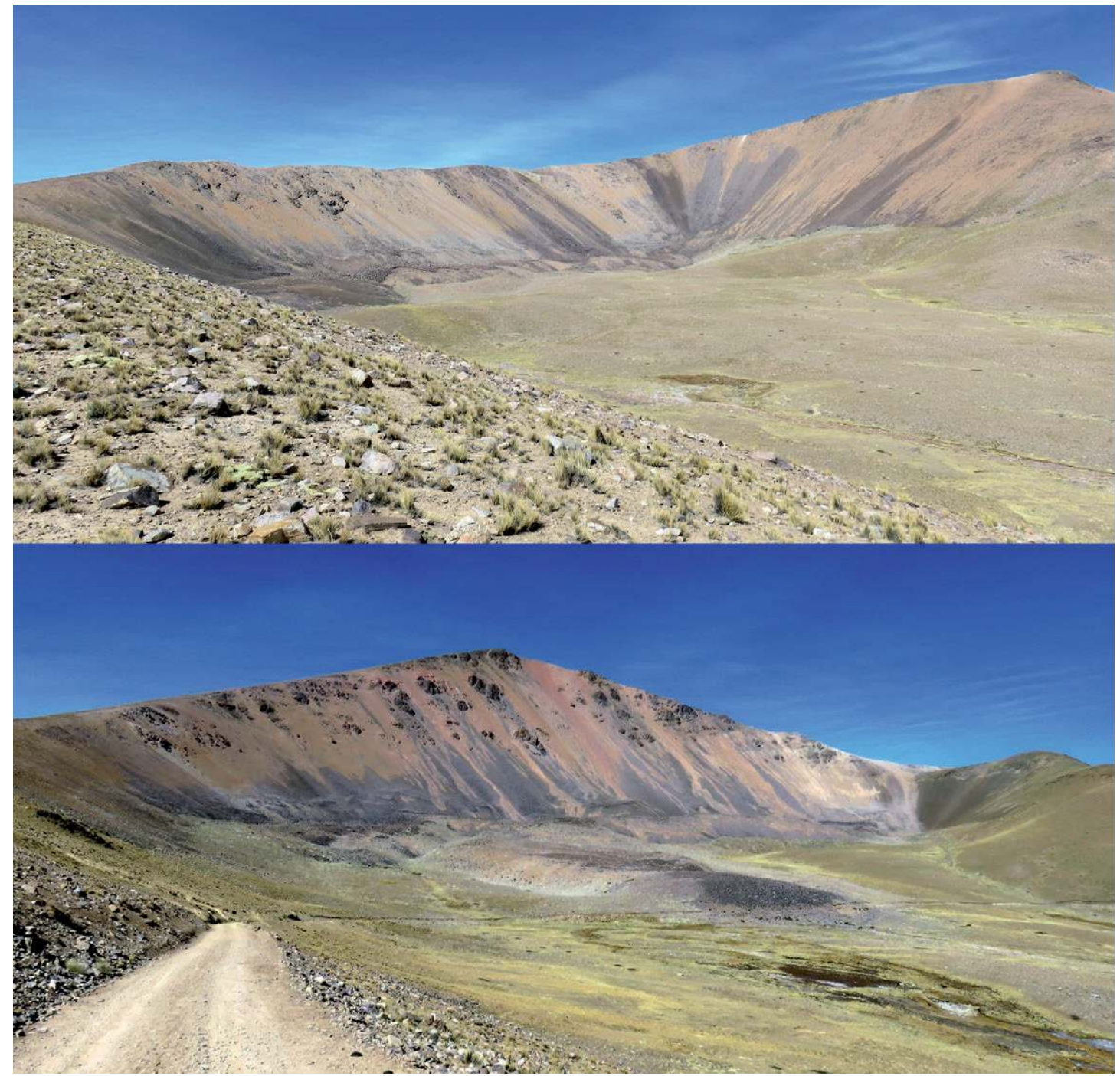

Figura 2. Cuencas criogénicas en estudio: Cuenca Norte (arriba) y Cuenca Sur (abajo).

- Gelifracción.- Es el principal proceso de meteorización en estos ambientes fríos, afectando por igual a los diversos tipos de rocas. Consiste en la desintegración mecánica de rocas debido a la presión ejercida por el agua que se halla a temperaturas bajo cero en poros y/o fracturas. Los bloques que conforman las geoformas más importantes como los glaciares de escombros y prótalus rampart son producto de la gelifracción, estos tienen tamaños de $50 \mathrm{~cm}$ en promedio.

- Suelos rastrillados. - Marcan la presencia de hielo acicular y ciclos de congelamiento y descongelamiento. Son suelos que presentan sobre su superficie marcas longitudinales como una especie de grietas, cuya disposición se da perpendicular a la pendiente y con dimensiones que varían desde unos pocos milímetros hasta $40 \mathrm{~cm}$.

- Estructura porridge.- Se forman en zonas donde emerge agua, como laterales de glaciares de escombros, que está cargada con material fino. Esta estructura indica un flujo viscoso de materiales que no tendrían cohesión en un estado descongelado. 


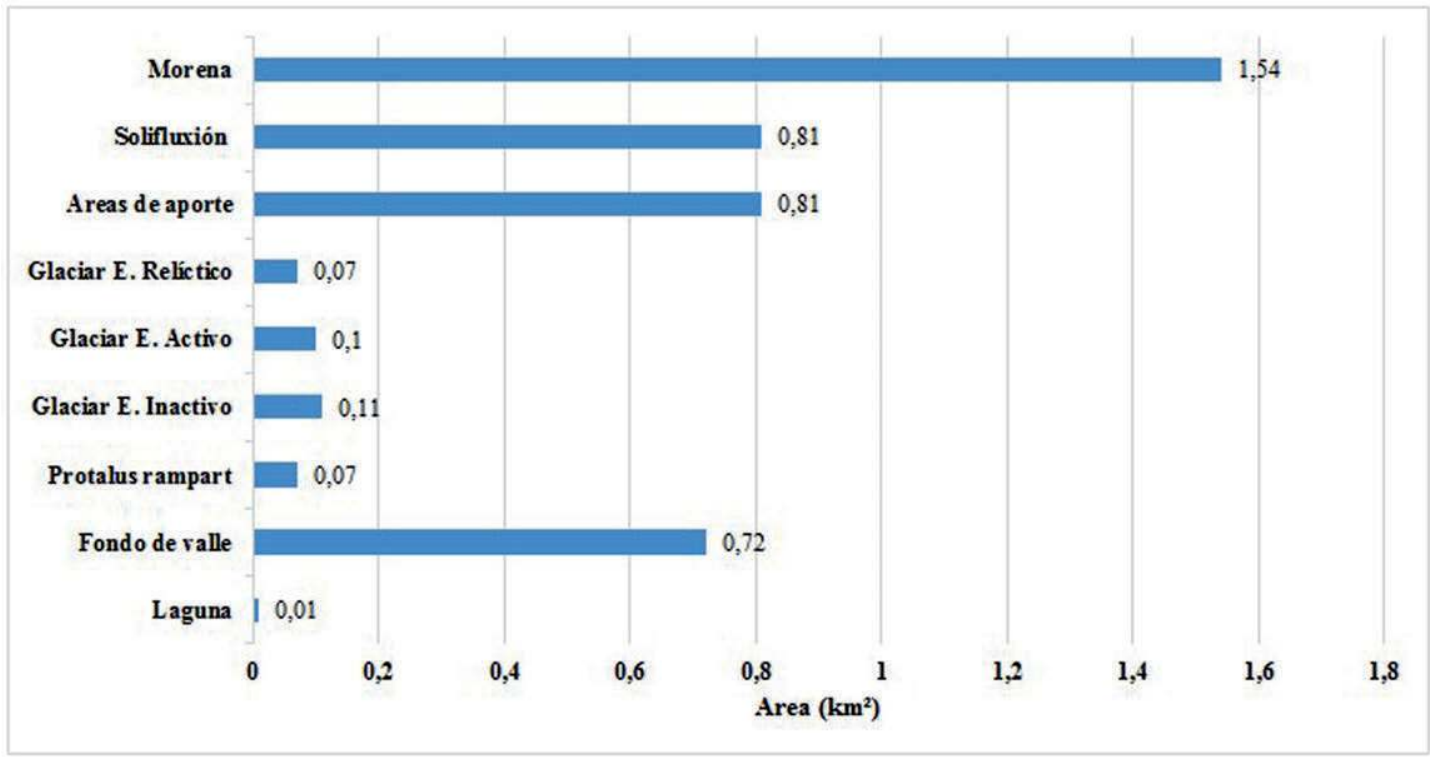

Figura 3. Área de geoformas criogénicas.

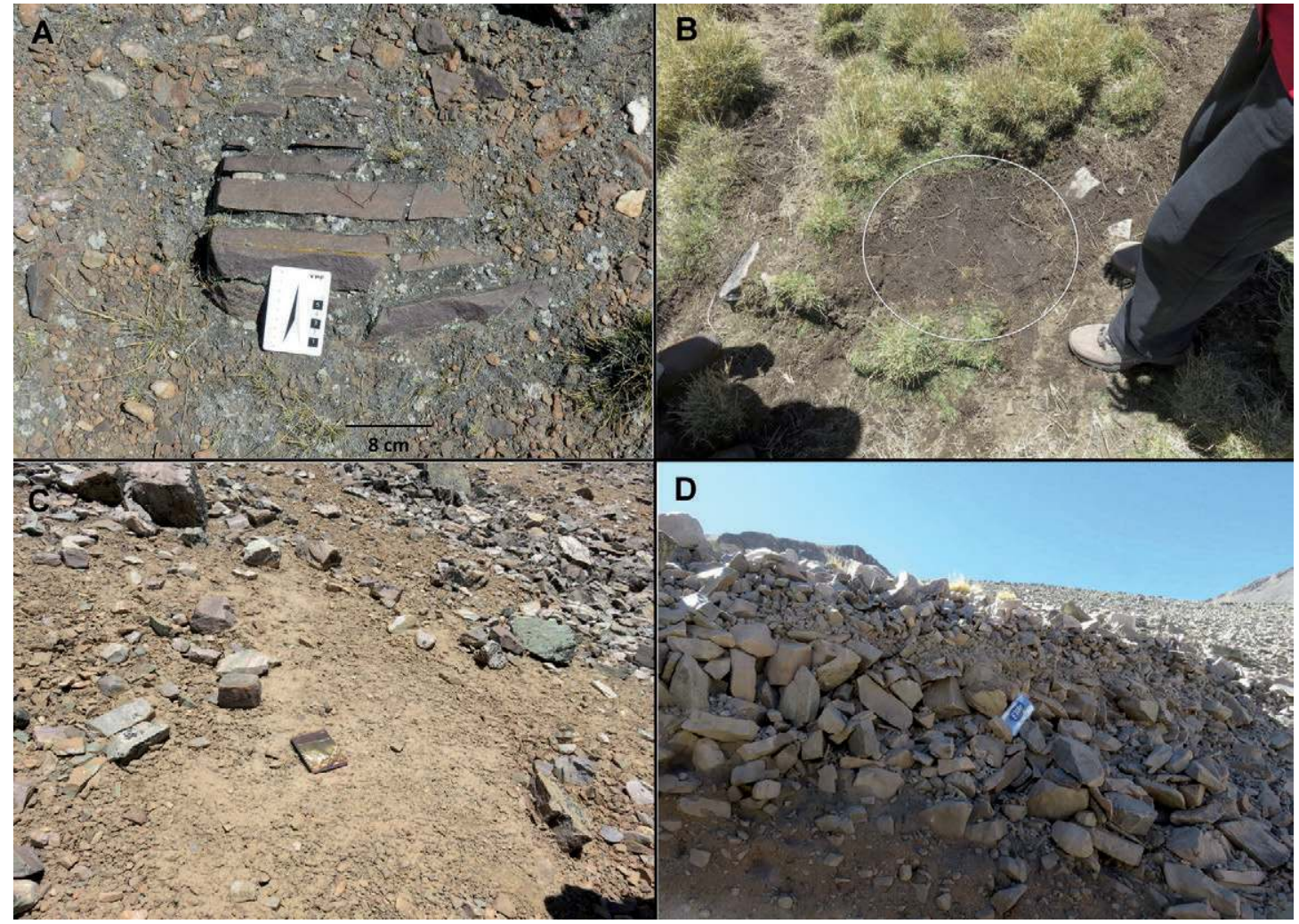

Figura 4. Geoformas y procesos menores: A) Gelifracción. B) Suelo rastrillado. C) Estructura porridge. D) Selección vertical.

- Selección vertical.-Es el ordenamiento que puede producirse en los sedimentos como consecuencia de repetidos ciclos de congelamiento y descongelamiento. En esta región es la selección criogénica típica, con sedimentos arenosos o bloques en la parte superior y los finos por debajo. 
Las geoformas glaciales y periglaciales más importantes que se reconocieron en la zona de estudio y se representaron en el mapa geomorfológico (figura 5) son las siguientes:

- Circos glaciarios.- Son depresiones semicirculares de paredes escarpadas y fondo cóncavo que se han formado en una montaña por la acción erosiva del hielo de un glaciar. Los circos glaciares crean un terreno montañoso muy característico en estos ambientes, se unen entre sí por crestas sinuosas de bordes agudos. Están bien definidos en ambas cuencas, la cuenca norte tiene mayor extensión areal y la cuenca sur posee paredes más escarpadas, con mayores pendientes. Estas paredes separan un circo de otro y además conforman una divisoria de aguas.

- Morenas.- Son acumulaciones de till, sedimentos detríticos depositados por el hielo glacial. Estos depósitos están formados por bloques heterométricos, angulosos y con poca matriz fina (figura 6). Los depósitos morénicos descriptos en el sector de trabajo corresponden a morenas laterales, donde se observan dos niveles, con sus crestas, bien definidas para ambas cuencas. En las morenas más antiguas se pueden

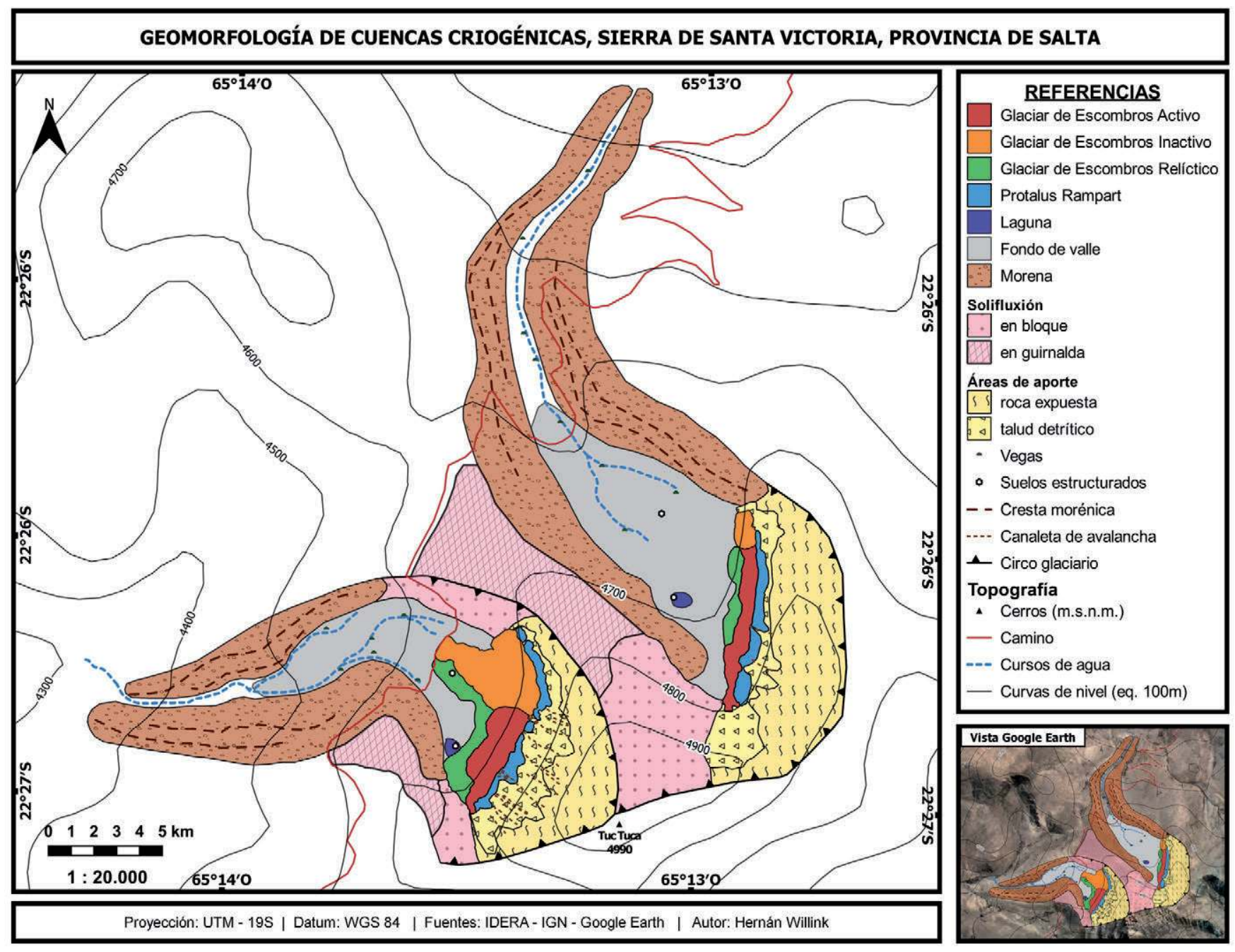

Figura 5. Mapa geomorfológico. 
observar algunos efectos de los procesos periglaciales superpuestos (solifluxión en guirnaldas, crioclastesis, etc.), lo que no se pudo distinguir en las morenas más jóvenes. Debido a la ausencia de dataciones, las edades de los depósitos de las fases glaciales son especulativas, se tomaron en consideración los métodos relativos de datación de depósitos glaciarios. En este caso se utilizó la posición topográfica y los rasgos geomorfológicos superficiales de las morenas para definir su antigüedad.

En la cuenca norte, la altitud más baja de la morena está en los 4.355 m.s.n.m., y la más alta en 4.710 m.s.n.m. En la cuenca sur, estos valores son de 4.350 y 4.660 m.s.n.m., para lo más bajo y alto, respectivamente.

- Glaciares de escombros.- Activos, inactivos y relícticos, que serán descriptos con mayor profundidad en la siguiente sección.

- Prótalus rampart.- Es un relieve de detrito que se desarrolla a lo largo de una ladera en los márgenes inferiores de un manchón de nieve perenne; se asume que los prótalus rampart forman parte de la evolución de un glaciar de escombros y son una forma incipiente de éstos. Cuando alcanzan un tamaño superior a $0,01 \mathrm{~km}^{2}$ y denotan movimiento pendiente abajo pueden ser considerados glaciares de escombros. Se acumulan en la parte baja de los taludes y parte superior de glaciares de escombros, alimentados por las canaletas de avalancha, tienen un buen desarrollo en ambas cuencas (figura 6).

Presentan pendientes en sus frentes de $30^{\circ}$ a $50^{\circ}$, que, en algunos casos, pueden ser mayores a los de los glaciares de escombros. La altitud promedio en la cuenca norte es de 4.730 m.s.n.m., y en la cuenca sur de 4.710 m.s.n.m.

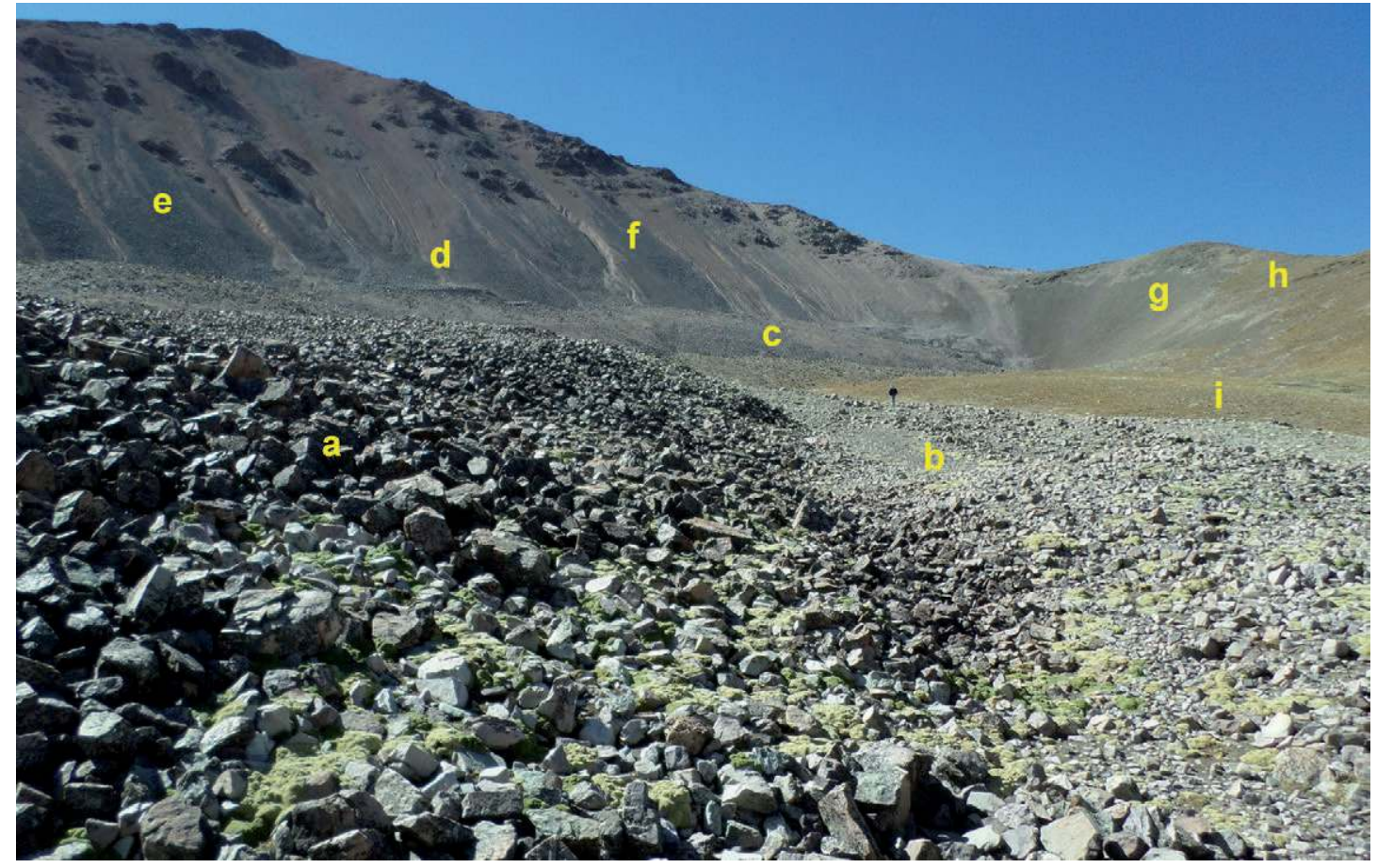

Figura 6. Geoformas principales en Cuenca Sur: a) Glaciar de escombros inactivo. b) Glaciar de escombros relíctico. c) Glaciar de escombros activo. d) Prótalus rampart. e) Talud detrítico. f) Canaleta de avalancha. g) Solifluxión en bloques. h) Solifluxión en guirnalda. i) Morena. 
- Taludes detríticos.- Son mantos de derrubios que recubren las laderas de las montañas principalmente en sus partes medias y bajas (figura 6). Estas acumulaciones rocosas se caracterizan por tener material más grueso y anguloso en la base, y mayor cantidad de finos en la parte superior. En los taludes de mayor longitud, que van de 120 a $180 \mathrm{~m}$, es donde mejor se pueden observar estas diferencias texturales. Los taludes constituyen la principal zona de aporte de los glaciares de escombros, constituidos por materiales fragmentados y arrancados de rocas en la parte superior.

- Solifluxión.- Es el movimiento lento, ladera abajo de materiales saturados descongelados, producto de dos fenómenos importantes: el levantamiento de las partículas del suelo por crecimiento de hielo acicular, que caen con el descongelamiento y la reptación propiamente dicha del suelo descongelado y saturado.

Se identificaron lóbulos en bloques y en guirnaldas (figura 6). Los primeros, en general, aparecen en la zona de estudio a mayor altura sobre las laderas de la cuenca, con respecto a la solifluxión en guirnaldas, y en pendientes mayores, sus tamaños pueden llegar a ser de gran dimensión, alcanzando los $120 \mathrm{~m}$ de largo y $100 \mathrm{~m}$ de ancho. Esto se debe a que la velocidad de movimiento en el centro del lóbulo es superior a la de los márgenes, es por esto que se alargan en el sentido de la máxima pendiente. La solifluxión en guirnaldas, en cambio, se manifiesta en zonas con pendientes más suaves, y a menor altura, asociadas siempre a la vegetación con los frentes demarcados por gramíneas. Tienen tamaños menores en relación a los presentados por los lóbulos en bloques, alrededor de $20 \mathrm{~m}$ de largo y $15 \mathrm{~m}$ de ancho, o menores aún.

- Canaletas de avalancha.- En las áreas cumbrales, las rocas que se encuentran alteradas por crioclastía son propensas a caer por gravedad, de esta forma el criosedimento desciende formando canales por medio de los cuales son transportados a niveles inferiores. Están desarrolladas principalmente en la cuenca sur, muchas son canaletas de un largo (100 a $150 \mathrm{~m})$, ancho $(1 \mathrm{a} 5 \mathrm{~m})$ y profundidades considerables (figura 6). En las zonas de mayor pendiente forman un único canal o surco, pero en zonas más bajas y de menor pendiente pueden presentar formas digitadas o ramificadas. Estas canaletas pueden terminar en prótalus rampart, que son formas embrionarias de glaciares de escombros, o directamente terminar y alimentar a estas geoformas.

- Suelos estructurados.- Son una combinación de procesos en donde intervienen el levantamiento por hielo acicular, selección, reptación del suelo, deshidratación y contracción térmica, por la acción del congelamiento y del descongelamiento, que determina el origen de estas formas superficiales muy particulares. En el área estudiada, tienen patrones morfológicos variados como redes, polígonos o círculos. Se manifiestan en zonas de baja pendiente, con diámetros de 15 a $30 \mathrm{~cm}$ y, en algunos casos, pueden mostrar una selección horizontal. Una particularidad se presenta sobre la superficie seca de lagunas pro-glaciares, donde estos suelos tienen un mayor grado de selección, con bordes de textura gruesa y el centro de material más fino. Asociados a estos suelos aparecen, muy comúnmente, los procesos de extrusión, con material fino originado por crioturbación (figura 7). 


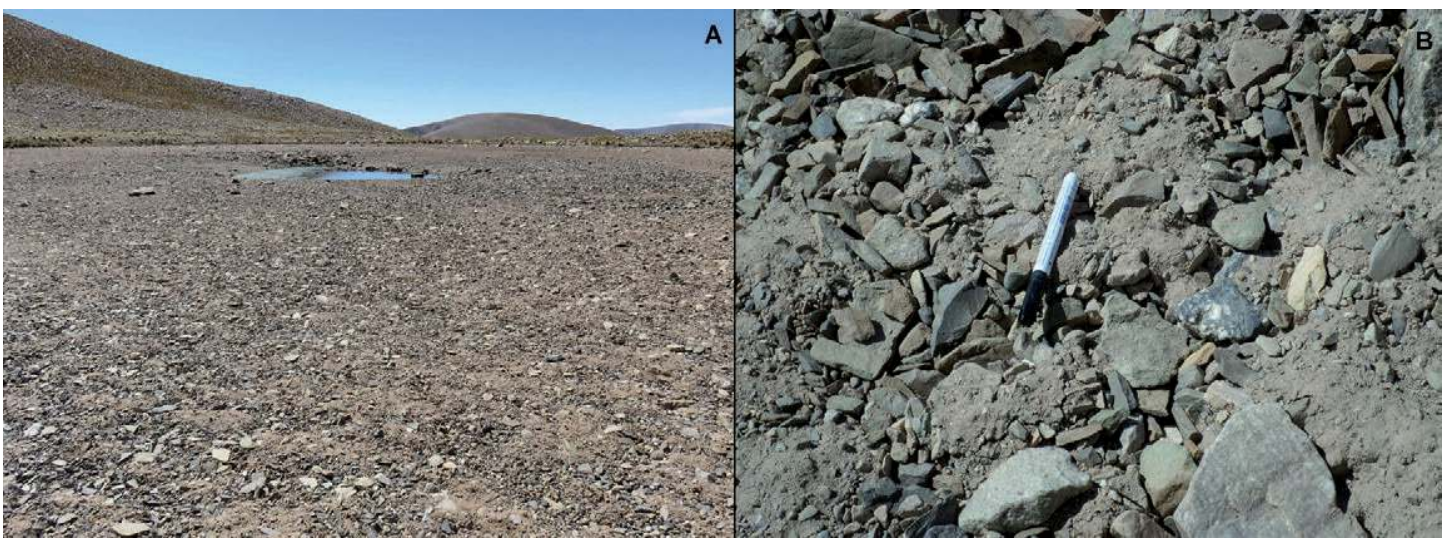

Figura 7. Suelos estructurados: A) No seleccionados sobre superficie de laguna. B) Seleccionado con procesos de extrusión.

- Vegas o turberas.-Son ecosistemas semiacuáticos cenagosos caracterizados por presentar una acumulación de materia orgánica y procesos sedimentarios en aguas estancadas. Son denominadas minerotróficas si se alimentan de agua proveniente de cursos de agua. Están formadas por vertientes o cauces originados por el descongelamiento de suelo criogénico, y cuando el agua tiene dificultades de percolación y escurrimiento al encontrar lechos sedimentarios impermeables. En el caso de las observadas en la zona de estudio, están asociadas hidrológicamente a los glaciares de escombros, desarrolladas en zonas cercanas, aguas abajo de pequeños cauces que nacen de los laterales o frentes de estas geoformas (figura 8). En algunos sectores, las vegas llegan a un tener grandes dimensiones. En épocas frías pueden estar congeladas.

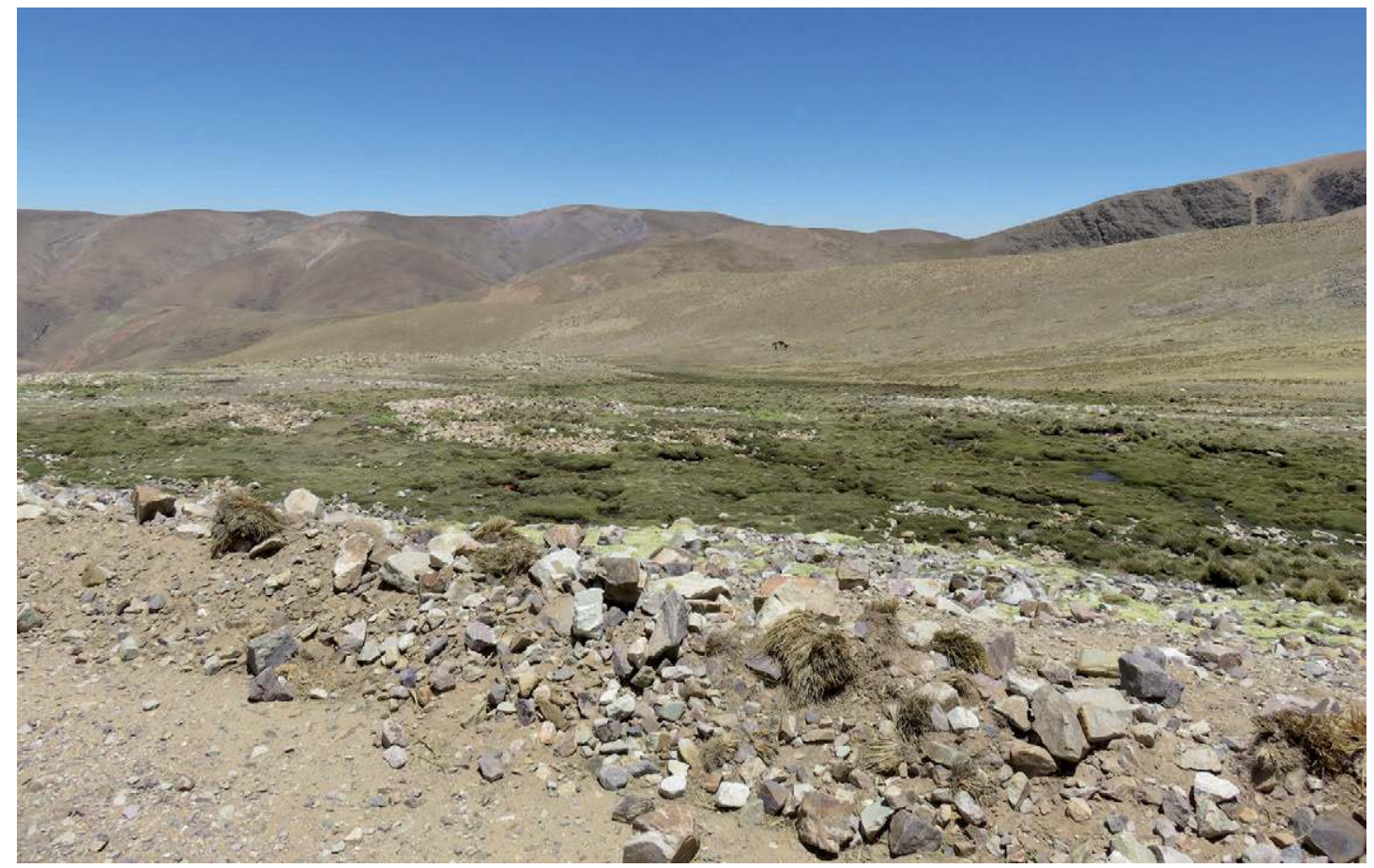

Figura 8. Vegas o humedales. 
- Lagunas.- Son lagunas someras pro-glaciares de escombros que tienen la misma relación hidrológica que las vegas, es decir, son alimentadas por pequeñas vertientes que salen del fondo o frente de glaciares de escombros. En verano pueden aumentar su tamaño y en invierno permanecen con poca agua o secas, esto puede evidenciarse con algas a distintos niveles (figura 9), que marcan variaciones estacionales en su contenido hídrico.

\section{Características de los glaciares de escombros}

Un glaciar de escombros, también denominado glaciar rocoso o litoglaciar, es una mesoforma criogénica de permafrost de montaña, sobresaturada en hielo que, si es activa, se mueve pendiente abajo por gravedad, reptación y deformación de este permafrost. Estos tipos de glaciares son masas de fragmentos o bloques de roca y material fino que yacen en una pendiente y contienen hielo intersticial (entre los intersticios del suelo o roca), o partes con hielo macizo (grandes masas de hielo presentes en cualquier espacio abierto dentro del suelo) y presentan evidencias de

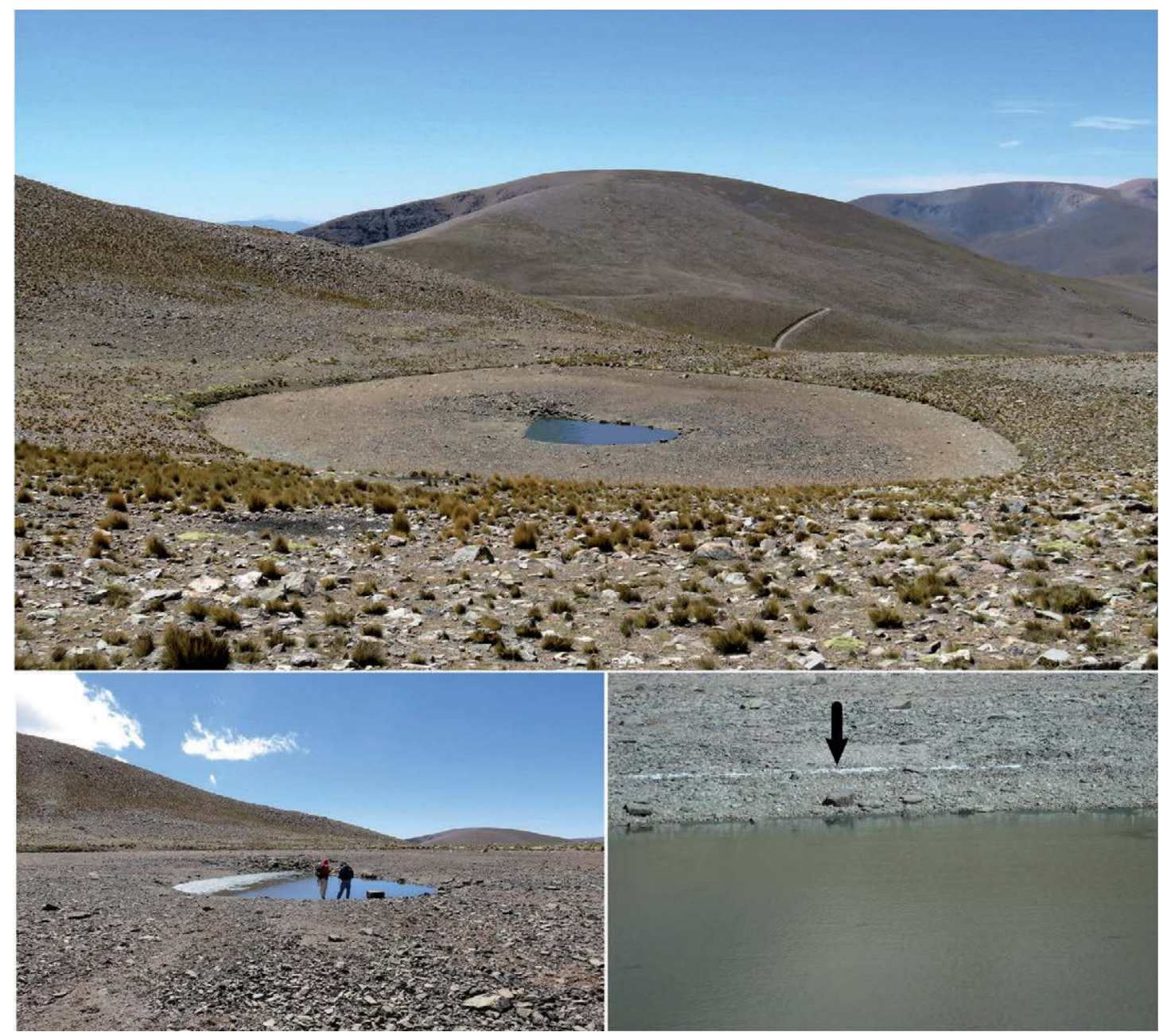

Figura 9. Laguna pro-glaciar de escombros, la flecha muestra algas que indica un nivel de agua antiguo. 
movimiento pasado o presente. Generalmente se menciona que los glaciares de escombros están activos o inactivos para expresar su movimiento y criodinámica. Los glaciares de escombros están activos cuando presentan frentes de alta pendiente con ángulos mayores a los de reposo, la mayoría presentan crestas transversales en superficie, estos cuerpos de detrito y hielo se mueven por la ladera, valle abajo formando lenguas o lóbulos, y están inactivos cuando todavía conservan su contenido de hielo, pero han dejado de moverse (Barsch, 1996).

La presencia de estas geoformas representa las expresiones máximas de los ambientes periglaciales y se encuentran directamente relacionados con la presencia de permafrost andino. La importancia de los glaciares de escombros en estas regiones radica en que tienen elevado valor hidrológico ya que constituyen invaluables reservas de agua dulce (Corte, 1976, 1978; Haeberli, 1985; Brenning, 2005).

De las 33 geoformas reconocidas en la zona de estudio, 6 de ellas son glaciares de escombros, identificando 3 de estos cuerpos en cada una de las dos cuencas. En la cuenca norte, los glaciares de escombros ocupan una superficie de 7,88 $\mathrm{Ha}$, y se ubican entre los 4.686 m.s.n.m. y los 4.785 m.s.n.m., como altura mínima y máxima, respectivamente. En la cuenca sur, el área ocupada por estas geoformas es de 20,33 Ha, y las alturas varían entre los 4.610 m.s.n.m. y 4.715 m.s.n.m.

De acuerdo al grado de actividad o dinámica, se pudieron diferenciar tres tipos de glaciares de escombros: activos, inactivos y relícticos (figura 10).

Los glaciares de escombros activos de la cuenca norte (figura 11), se caracterizan por tener pendientes de frentes que superan los $35^{\circ}$, llegando hasta los $37^{\circ}$, tienen un cierto grado de convexidad y desmoronamiento de bloques en sus frentes, con relieves superficiales medianamente conservados y, en general, están poco vegetados, debido a la dinámica de estos glaciares de escombros, como consecuencia de la existencia de permafrost reptante que almacena gran contenido en hielo.

Por su parte, los glaciares de escombros inactivos de esta cuenca, que todavía conservan su contenido de hielo, evidenciado por pequeños hilos de agua que surgen de estos, tienen frentes deteriorados y vegetados, con frentes promedio de $31^{\circ} \mathrm{y}$ presentan algunos hundimientos por pérdida del hielo (figura 12).

En la cuenca sur, los glaciares de escombros activos tienen frentes con pendientes abruptas entre $\operatorname{los} 35^{\circ}$ a $41^{\circ}$ (figura 6 y 13), estos frentes tienen formas convexas

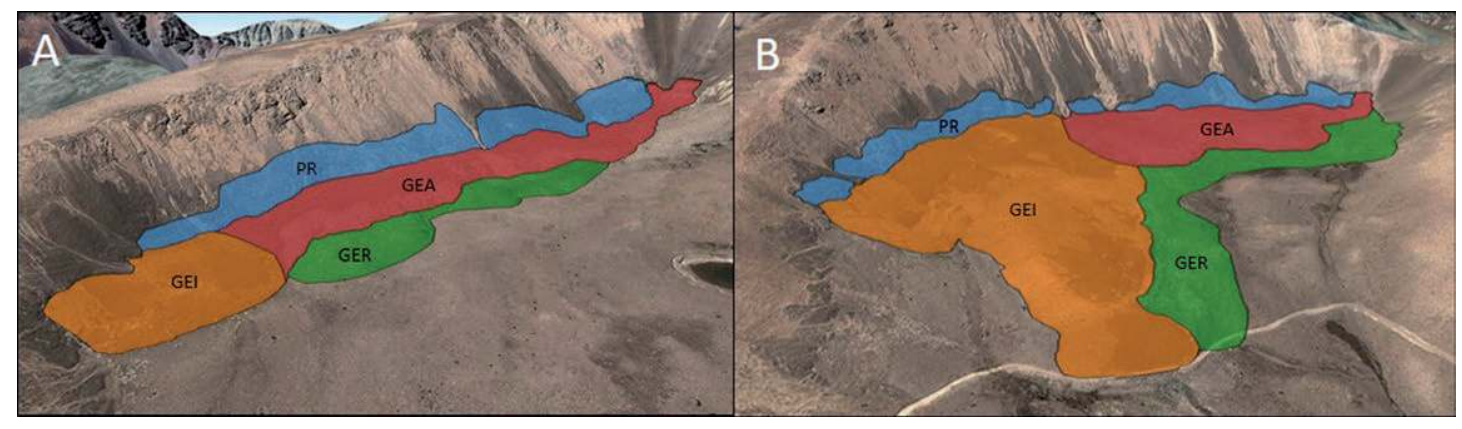

Figura 10. Distribución espacial de los diferentes tipos de glaciares de escombros de acuerdo a su actividad y de prótalus rampart en las Cuenca Norte (A) y Sur (B). GEA: glaciar de escombros activo. GEI: glaciar de escombros inactivo. GER: glaciar de escombros relíctico. PR: prótalus rampart. Base cartográfica: imagen de Google Earth. 


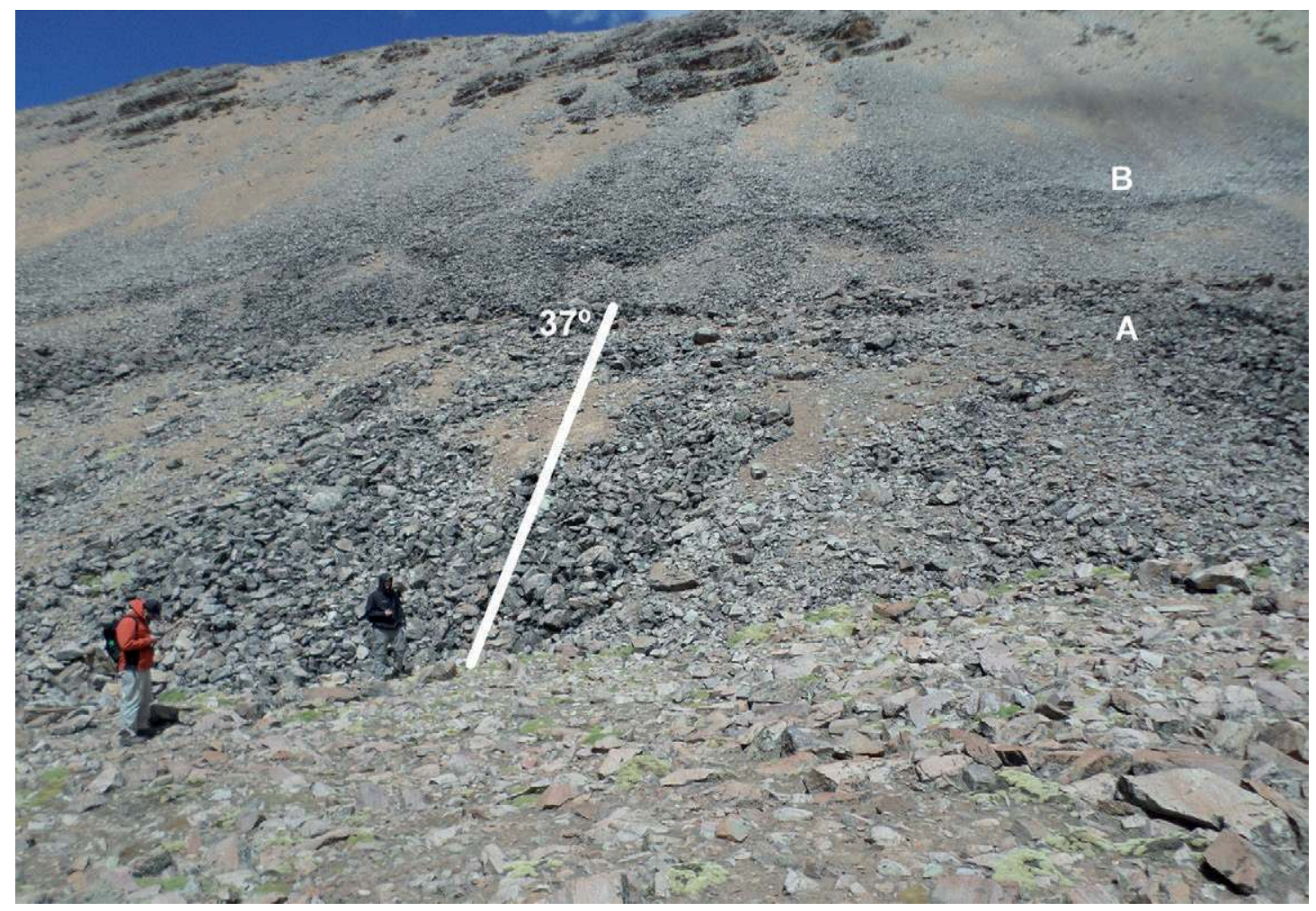

Figura 11. Pendiente de glaciar de escombros activo (A) y prótalus rampart por encima (B).

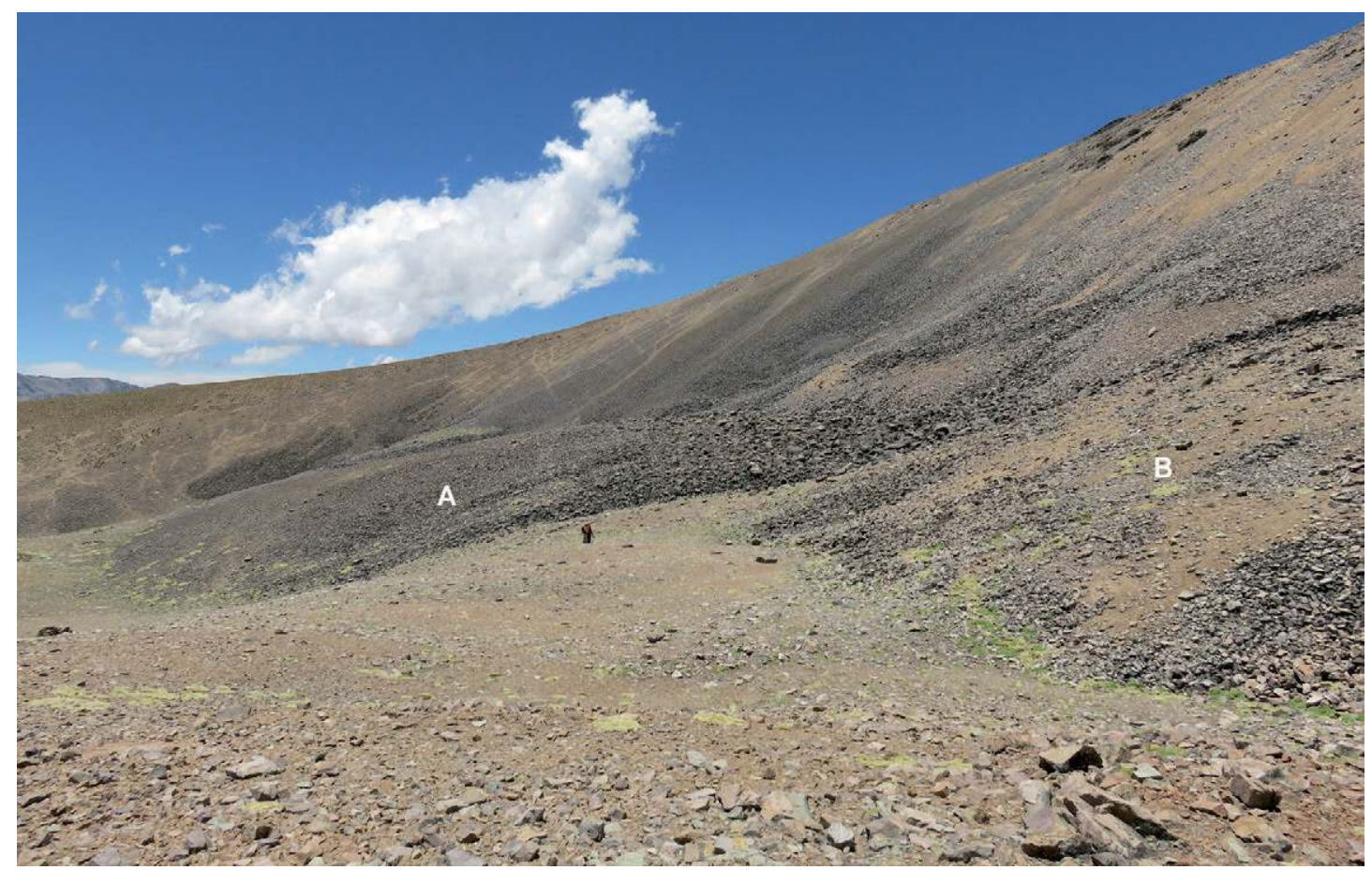

Figura 12. A) Glaciar de escombros inactivo; B) Frente de un glaciar de escombros activo.

mejor desarrolladas, acumulación de bloques debajo de las pendientes que caen por el movimiento y, arrugas o arcos perpendiculares al flujo. Por otro lado, los inactivos se caracterizan por tener relieves superficiales deteriorados (figura 14), con grandes 


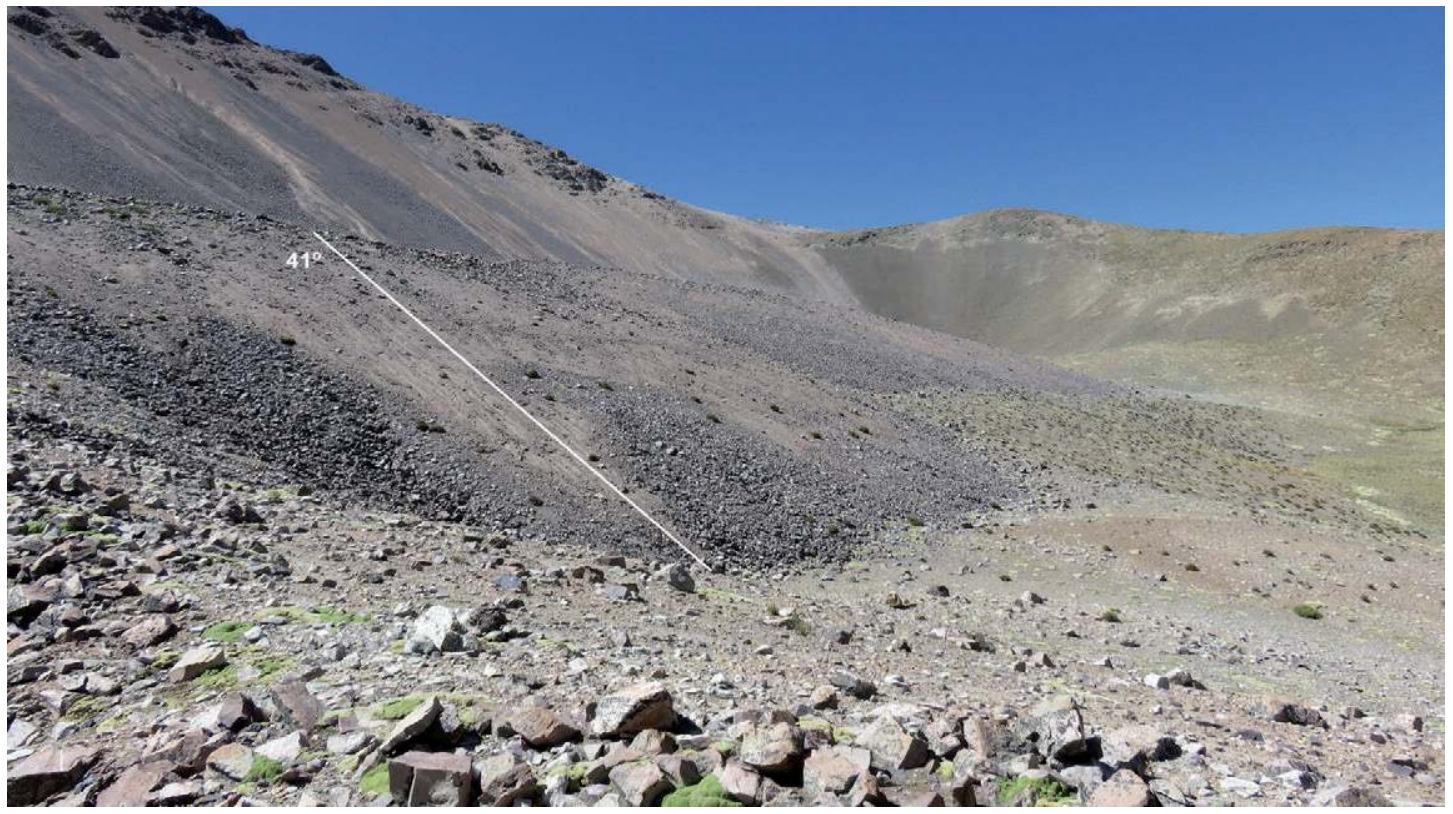

Figura 13. Pendiente de frente de glaciar de escombros activo en Cuenca Sur.

hundimientos o depresiones, desarrollo de vegetación y suelos estructurados con procesos de extrusión. Las pendientes de estas geoformas inactivas son de $30^{\circ}$.

Los glaciares de escombros relícticos, comparten sus características en las dos cuencas, están fuertemente vegetados y, con sus frentes y superficies suavizados con ángulos muy bajos (figura 6).

En la tabla 1 se resumen los principales parámetros de los glaciares de escombros en cada cuenca.

Las geoformas se han clasificado como glaciares de escombros y prótalus coalescentes (figura 15), los cuales al estar constituidos por una parte activa y una inactiva se consideran multiunidad. Esto habla de una degradación diferencial asociada a los factores de exposición solar, que varía en función del arco de la cuenca y laderas, afectando de forma dispareja a los distintos sectores.

$\mathrm{Al}$ ser glaciares de escombros que reciben los detritos de varias fuentes de alimentación, se han clasificado como glaciares de escombros multiraíz.

Por su origen, se trata de glaciares de escombros de talud, formados principalmente por gelifractos provenientes de estos taludes, paredes del circo glaciario y de las canaletas de avalancha que deslizan el material.

Tabla 1. Principales parámetros de glaciares de escombros (GE)

\begin{tabular}{|c|c|c|c|c|c|c|}
\hline \multirow{2}{*}{ Parámetros } & \multicolumn{3}{|c|}{ Cuenca Norte } & \multicolumn{3}{c|}{ Cuenca Sur } \\
\cline { 2 - 7 } & GE Activo & GE Inactivo & GE Relíctico & GE Activo & GE Inactivo & GE Relíctico \\
\hline $\begin{array}{c}\text { Altura mínima } \\
\text { (m.s.n.m.) }\end{array}$ & 4.695 & 4.686 & 4.690 & 4.670 & 4.610 & 4.615 \\
\hline $\begin{array}{c}\text { Altura máxima } \\
\text { (m.s.n.m.) }\end{array}$ & 4.785 & 4.713 & 4.720 & 4.715 & 4.710 & 4.680 \\
\hline Superficie (Ha) & 4,55 & 1,3 & 2,03 & 5,78 & 9,6 & 4,95 \\
\hline
\end{tabular}




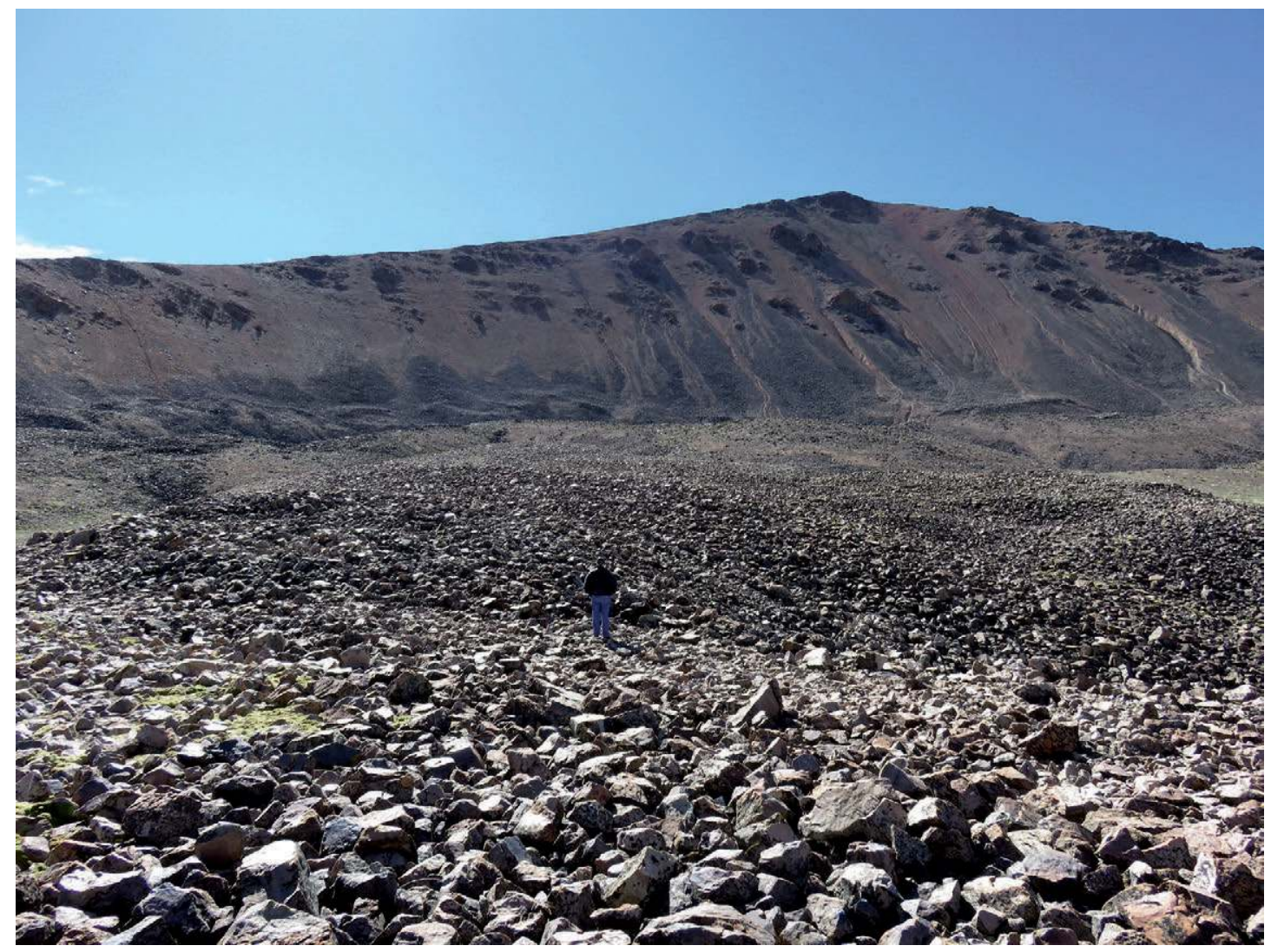

Figura 14. Relieve de la superficie de un glaciar de escombros inactivo, con hundimientos.

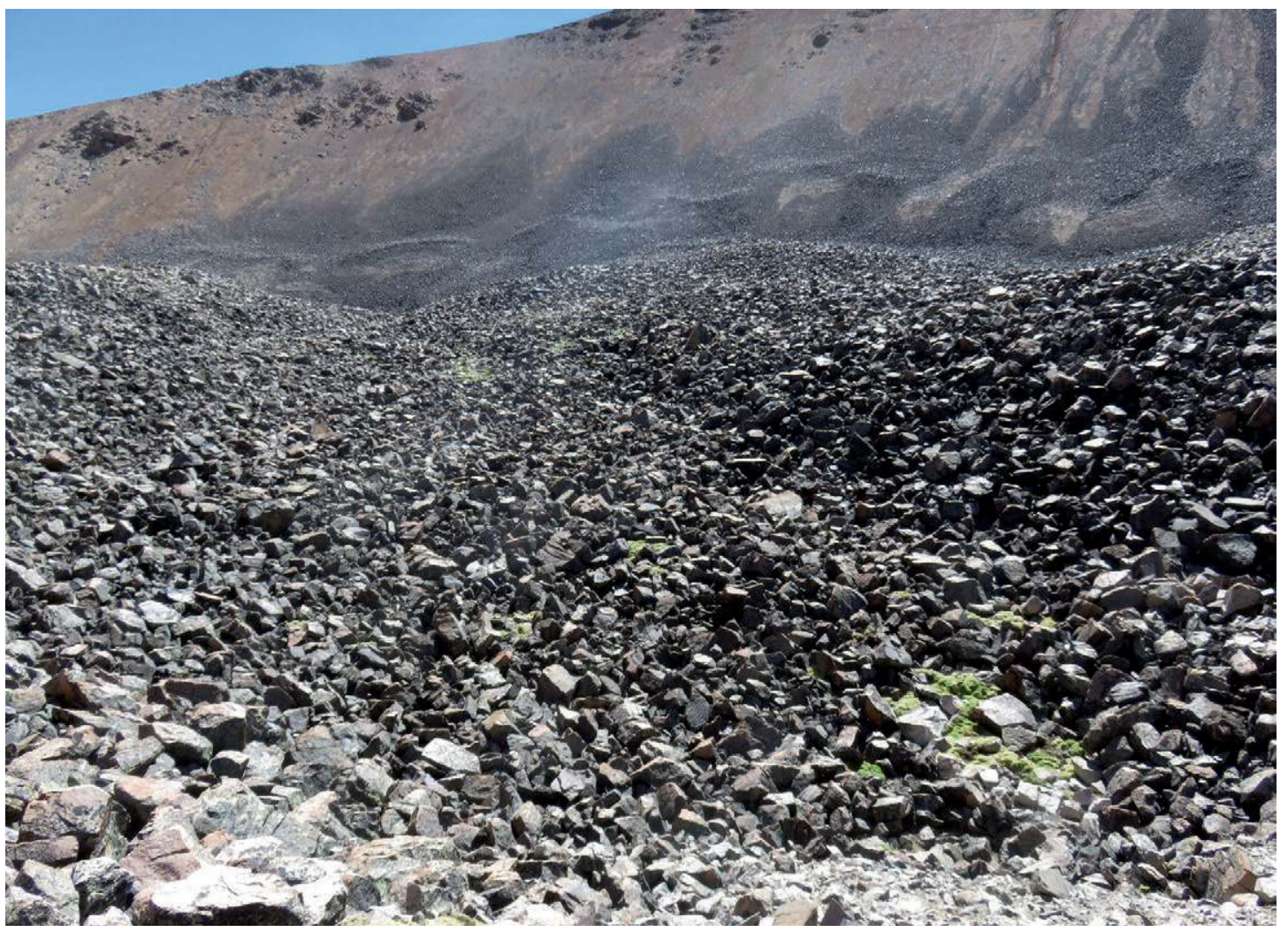

Figura 15. Sector de confluencia entre glaciares de escombros en Cuenca Sur. 
Desde el punto de vista de su morfometría, son principalmente lobulados o espatulados, desarrollados al pie de las laderas del valle, y en la cuenca sur también se presentan del tipo en lengua, ocupando parte del fondo de valle (figura 2).

\section{Análisis de las variables del terreno}

La distribución de los glaciares de escombros y geoformas periglaciales, en el ámbito de sierra de Santa Victoria, está controlada particularmente por factores topográficos. Dentro de estos factores se destacan la orientación y pendiente de las cuencas como variables importantes que influyen en los procesos y desarrollo de geoformas en la región de estudio (figura 16).
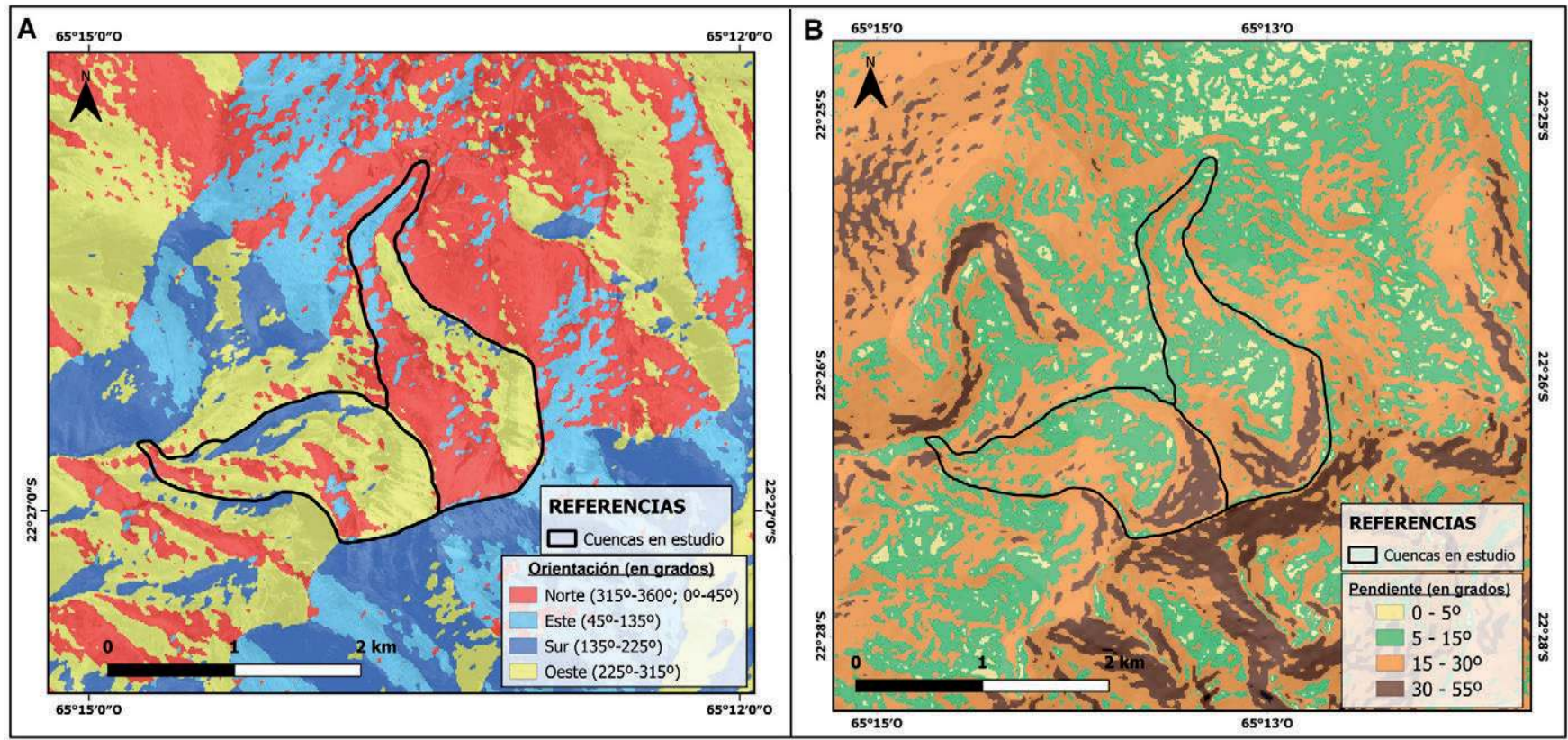

Figura 16. A) Mapa de Orientación; B) Mapa de Pendientes, de las cuencas en estudio.

Haciendo un análisis de las orientaciones de las principales geoformas como glaciares de escombros, prótalus y taludes detríticos, se determinaron las siguientes orientaciones preferenciales: $\mathrm{O}(46 \%), \mathrm{NO}(41 \%)$ y N (8\%) en las cuencas de estudio (Figura 17).

De la interpretación del mapa de pendientes se puede establecer que de las geoformas principales como glaciares de escombros y prótalus rampart corresponden a valores de pendientes entre $\operatorname{los} 15^{\circ}$ a $30^{\circ}$, y en la zona de aporte con los taludes detríticos, una pendiente promedio de $45^{\circ}$. Los glaciares de escombros, en la cuenca norte, poseen una pendiente superior promedio de $15^{\circ}$ y en la cuenca sur de $20^{\circ}$.

En base a estos mapas de análisis del terreno se pudo observar que, si bien la cuenca sur es de menor extensión con respecto a la cuenca norte, presenta un mayor desarrollo de geoformas periglaciales, debido, principalmente, al efecto de sombra que causan las laderas y arco de la cuenca por su altitud. Esto marca una 


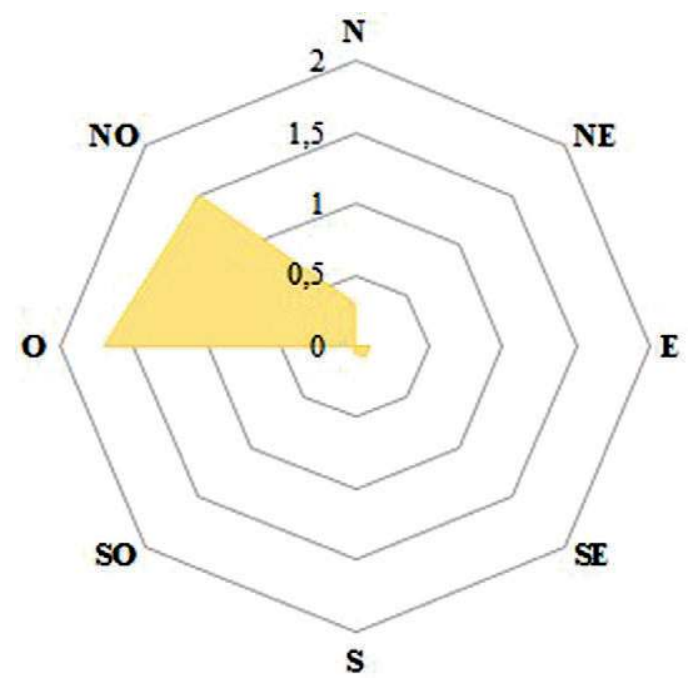

Figura 17. Orientación de las principales geoformas inventariadas, en términos de su área $\left(\mathrm{km}^{2}\right)$.

clara diferencia entre ambas cuencas y cómo influye este efecto de sombra, ya que la orientación principal en los dos casos es oeste-noroeste, orientaciones consideradas como cálidas, con mayor insolación y, por lo tanto, mayor temperatura, que dificulta o retrasa los procesos periglaciales de congelamiento.

\section{Degradación del permafrost}

La degradación del permafrost es una disminución natural o artificialmente inducida del espesor o de la extensión superficial del permafrost, que puede ser causada por un calentamiento climático o por cambios en las condiciones del terreno por actividades humanas (figura 18).

En la zona de estudio se pudieron identificar distintas geoformas o procesos que pueden evidenciar este fenómeno:

- Lagunas pro-glaciares: estas son rasgos geomorfológicos que denotan el deterioro del complejo sistema térmico que sostiene la presencia de permafrost de montaña en estas latitudes (Ahumada et al., 2015). Se forman por acumulación de agua en zonas favorables (deprimidas) que derivan de pequeñas vertientes del fondo de los glaciares de escombros. Una diferencia se destaca en la cuenca norte donde se puede observar a esta laguna con acumulación de agua y la evidencia de sus fluctuaciones estacionales con la presencia de algas, por el contrario, en la cuenca sur se exhibe totalmente seca.

- Humedales o vegas: como señala Ahumada (2007), el crecimiento de estos humedales es algo generalizado en estos tipos de ambientes en sierra de Santa Victoria, producidos por el incremento de caudales del sistema hidrológico que los alimenta, a expensas del descongelamiento definitivo de los núcleos de hielo de geoformas vecinas. Estas formas periglaciales están ampliamente desarrolladas en las cuencas en estudio, principalmente en zonas de topografías bajas, como valles o depresiones. 


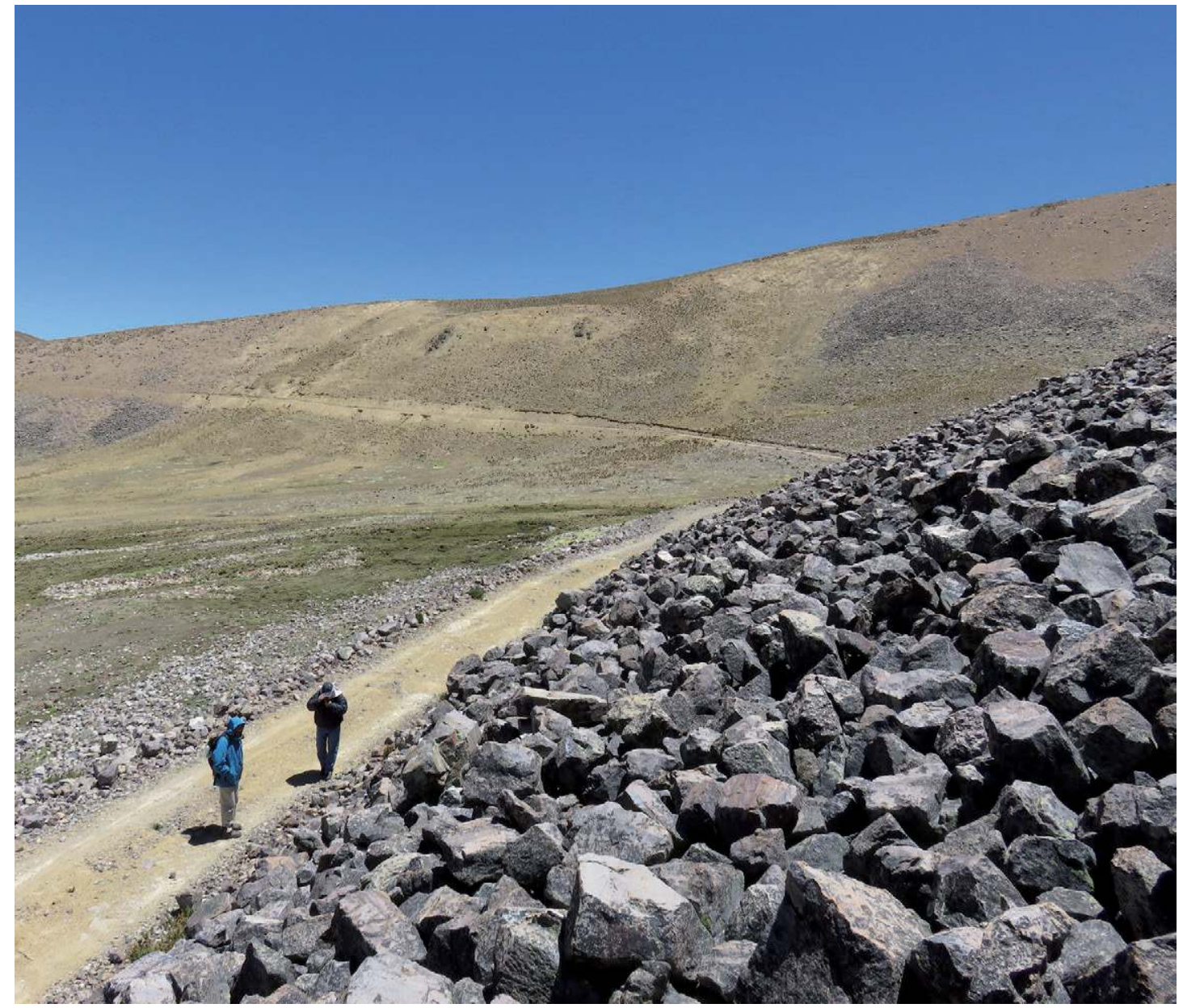

Figura 18. Frente de glaciar de escombros cortado por camino.

- Termokarst.- Evidenciado por hundimientos o depresiones en sectores de los glaciares de escombros, su presencia indica cambios en las condiciones climáticas que regulan la estabilidad de dicha geoforma. Esta degradación aparece en ambas cuencas con un fuerte deterioro con hundimientos, también reconocibles a través de imágenes satelitales.

- Deterioro de capa activa.- El deterioro de la capa activa está evidenciado por la presencia de cicatrices de deslizamiento, con formas concoides, en los frentes de los glaciares de escombros o prótalus. Esto genera el incremento del ingreso de calor en el núcleo del glaciar afectado (figura 19).

\section{DISCUSIÓN}

A modo general, este paisaje de alta montaña es el resultado de la acción de agentes exógenos cuaternarios de tipo glacial y periglacial, y del modelado posterior del ambiente periglacial, que rige la morfodinámica local actual.

En cuanto a las evidencias del modelado glacial anteriormente mencionado, hay morenas bien preservadas y circos profundamente excavados, en el área de estudio. 


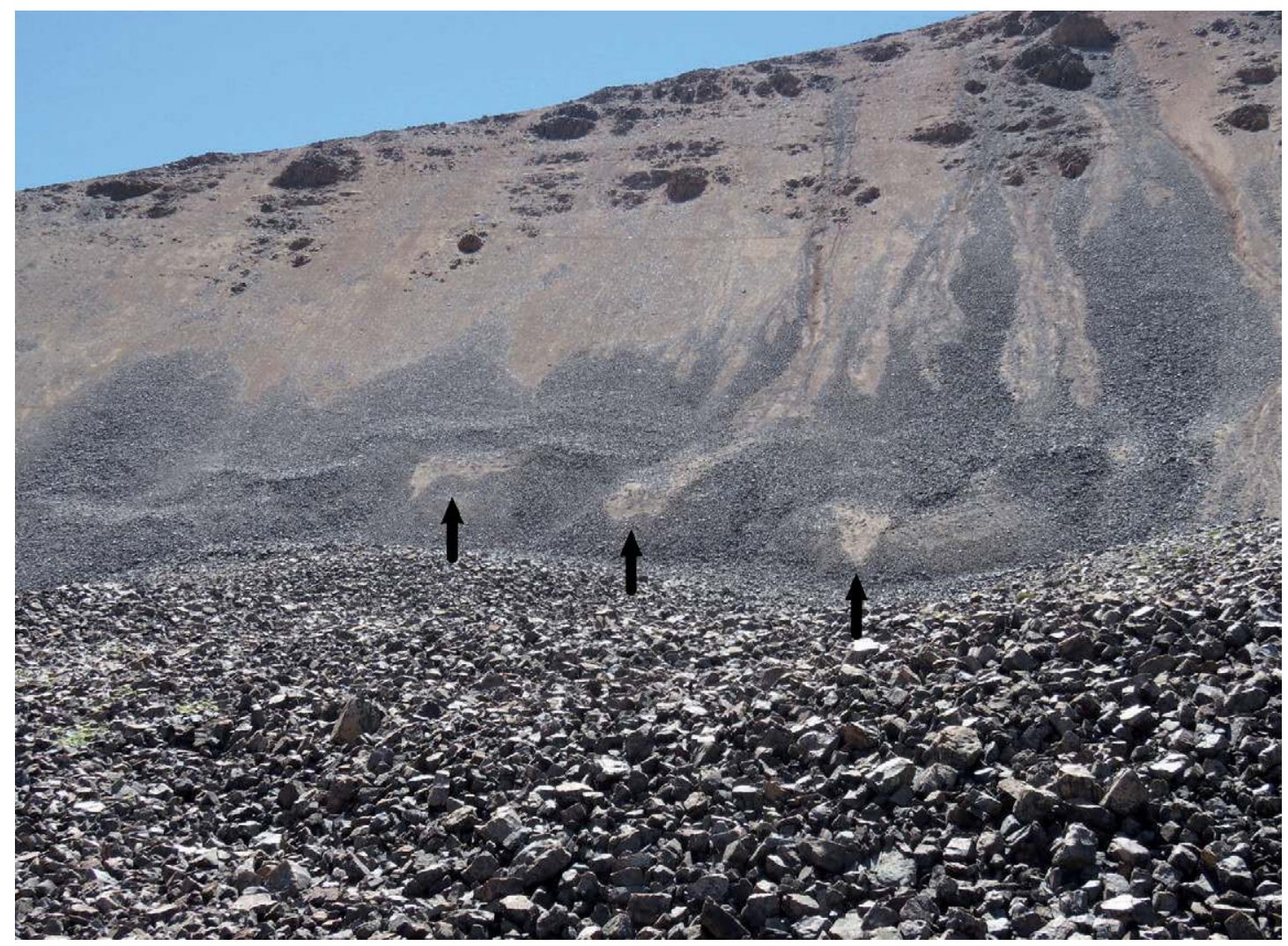

Figura 19. Degradación de capa activa, con cicatrices concoides de deslizamientos sobre frente de prótalus.

Los circos dejados por las glaciaciones pleistocénicas, ahora libres de hielo, han constituido un nicho ideal para el desarrollo de importantes glaciares de escombros, geoformas más notorias del ambiente periglacial (Barsch, 1996).

Para la clasificación de los glaciares de escombros según su actividad se han considerado criterios morfológicos, entre los cuales se destacan el ángulo del talud frontal, presencia y abundancia de vegetación, apariencia geomorfológica del frente (Roer y Nyenhuis, 2007). Estos indicadores son indirectos.

Debido al nivel de detalle con el que se trabajó en el área de estudio, en cuanto a las observaciones en el terreno y a la escala de trabajo en el mapeo, se pudo determinar de manera fehaciente el grado de actividad de los glaciares de escombros de la zona en activos, inactivos y relícticos.

El uso de herramientas de geoprocesamiento puede ser útil para el análisis de variables del terreno, como la orientación y pendiente, que puedan influir en los distintos procesos y geoformas criogénicas.

Los registros de temperatura diaria extrapolada a 4.600 m.s.n.m. indican una temperatura media anual del aire de $+0,3^{\circ} \mathrm{C}$ (Ahumada et al., 2014), lo cual indicaría, al menos preliminarmente, un estado de desequilibrio entre los glaciares de escombros y el clima actual, que provocaría la degradación del permafrost. Los fenómenos de deterioro del permafrost indican la necesidad de planes de manejo organizado de los recursos en esta región de altura ante los posibles riesgos por efecto del calentamiento global. No obstante, los fenómenos de congelamiento del suelo 
son importantes y los glaciares de escombros activos mantienen sus propiedades geocriogénicas todavía.

\section{CONCLUSIONES}

Las características geomorfológicas del área de estudio, muestran de manera clara como han influido diferentes agentes morfogenéticos en la configuración actual del relieve. Esto se ve reflejado en la existencia de formas atribuibles directamente a la acción glacial, como circos y morenas, que actualmente presentan en superficie algunos rasgos más comunes de los sistemas de erosión de ambientes periglaciales. También se manifiesta por la importancia que adquieren algunas formas periglaciales como los glaciares de escombros identificados.

En las cuencas estudiadas se reconocieron 33 geoformas periglaciales y glaciales que cubren una superficie de $4,24 \mathrm{~km}^{2}$, siendo la cuenca sur la que posee un mayor desarrollo de estas geoformas. Se identificó una asociación importante de microformas y macroformas periglaciales, donde se destacan los glaciares de escombros por ser las expresiones máximas de estos ambientes criogénicos y se encuentran directamente relacionados con la presencia de permafrost andino.

La distribución de los glaciares de escombros y geoformas periglaciales, en el ámbito de sierra de Santa Victoria, está controlada particularmente por factores topográficos entre los que destacan la pendiente y orientación de las cuencas.

Se diferenciaron glaciares de escombros activos, inactivos y relícticos, de acuerdo a su grado de actividad. Estas geoformas se encuentran desde los 4.610 m.s.n.m., como piso altitudinal, hasta los 4.785 m.s.n.m. como mayor altura. Los glaciares de escombros activos son de mayor extensión en la cuenca sur, y poseen frentes con pendientes de mayor ángulo.

La orientación predominante de las cuencas estudiadas es la oeste-noroeste, orientación que, a pesar de ser de gran insolación, permite por el efecto de sombra generado por laderas, que los glaciares de escombros contengan hielo y puedan mantenerse como activos.

Los glaciares de escombros activos e inactivos constituyen una fuerte influencia en la hidrología actual de la región, son el origen de pequeños cauces estacionales que la mayoría de las veces, fomentan el crecimiento de turberas.

Se identificaron y describieron fenómenos de deterioro del permafrost como lagunas pro-glaciares, termokarst, vegas y deterioro de la capa activa en algunas geoformas con permafrost. Estos rasgos de degradación pueden ser incrementados por los efectos del cambio climático. Los mismos pueden ocasionar daños de importancia en las poblaciones ubicadas en el fondo de profundos valles y en caminos de altura que unen pequeñas villas rurales en este piso geocriogénico. Estos fenómenos impactan en la productividad, vías de comunicación y comercialización, energía e interfieren en los medios de vida de la población. El estado general actual de los glaciares de escombros, por lo menos en gran parte del sector, con las evidencias de hundimientos y depresiones, el deterioro de la capa activa, sumado a pequeños cauces que favorecen la formación de vegas y lagunas, indican este desequilibrio. 


\section{AGRADECIMIENTOS}

Los autores desean expresar su agradecimiento a la Fundación Miguel Lillo que proveyó los fondos necesarios mediante el Proyecto G-0032 y el apoyo logístico e instrumental para realizar todas las campañas a la región de trabajo. A los árbitros por sus comentarios acertados.

\section{BIBLIOGRAFIA}

Ahumada, A. L. 2007. El calentamiento global y sus manifestaciones en la criósfera de las altas montañas del norte argentino. Jornadas sobre Calentamiento Global en el Marco del Año Polar. Universidad Nacional del Comahue. Edición Especial Boletín Geográfico, Año XXIX 30: 57 - 69.

Ahumada, A. L. 2007. Geoindicadores criosféricos en los Andes Centrales del NW de Argentina. Acta Geológica Lilloana, 20 (1): 9 - 17.

Ahumada, A. L. 2008. El conocimiento de la Criósfera continental del NW de Argentina. Su comportamiento ante el Calentamiento Global. Anales 2008. Academia Nacional de Ciencias. Tomo XLII (1): 383-388. Buenos Aires.

Ahumada, A. L., Ibañez Palacios, G. P. y Páez, S. V. 2005a. High Mountain permafrost in the argentine subtropic. $19^{\circ}$ Colloquium on Latin American Geosciences. Terra Nostra 1: 9 pp, Potsdam, Alemania.

Ahumada, A. L., Ibañez Palacios, G. P. y Páez, S. V. 2005b. Los glaciares de escombros en el Noroeste Argentino, acuíferos de altura en riesgo ante los cambios globales. XX Congreso Nacional del Agua, CONAGUA-2005, III Simposio de Recursos Hídricos del Cono Sur, Versión digital, Mendoza.

Ahumada A. L., Ibañez Palacios, G. P., Carilla, J., Toledo, M. A. y Páez, S. V. 2015. Observaciones geomorfológicas en glaciares de escombros de los Andes tropicales de Argentina. Acta Geológica Lilloana XXVII (2): 63-76.

Ahumada, A. L., Ibañez Palacios, G. P., Toledo M. A., Carilla J. y Páez, S. V. 2014. El permafrost reptante, inventario y verificación en las cabeceras del río Bermejo. Geoacta 39(1): 123-137.

Ahumada, A. L., Ibañez Palacios, G. P., Toledo, M. A., Saccone, P., García, A. K., Páez, S. V. y González Díaz, L. N. 2017. La criósfera en el noroeste argentino. En: Muruaga, C. M. y Grosse, P. (Eds.), Ciencias de la Tierra y Recursos Naturales del NOA. Relatorio del XX Congreso Geológico Argentino, San Miguel de Tucumán: 851-872. ISBN 978-987-42-6666-8.

Ahumada, A. L., Páez, S. V., Ibañez Palacios, G. P. 2006. Rock Glaciers in the Andean Criolithozone at the $27^{\circ} \mathrm{S}$. Symposium on Climate Change: Organizing the Science for the American Cordillera (CONCORD): 51-52. Mendoza.

Armstrong, T., Roberts, B., Swithinbank C. 1997. Illustrated Glossary of Snow and Ice. Published with the support if UNESCO. Scott Polar Research Institute, Cambridge, UK, 60 p., 39 plates.

Barsch, D. 1996. Rockglaciers: 331. Springer, Berlín. 
Brenning, A. 2005. Geomorphological, hydrological and climatic significance of rock glaciers in the Andes of Central Chile $\left(33^{\circ}-35^{\circ}\right)$. Permafrost and Periglacial Processes 16: 231-240.

Cabrera, A. L. 1976. Regiones Fitogeográficas de Argentina. ACME, Buenos Aires. Argentina. 110 p. En: Mendoza y González, 2011.

Cogley, J. G., Hock, R., Rasmussen, L. A., Arendt, A. A., Bauder, A., Braithwaite, R. J., Jansson, P., Kaser, G., Möller, M. Nicholson, L. and Zemp, M. 2011. Glossary of Glacier Mass Balance and Related Terms. IHP-VII Technical Documents in Hydrology No. 86, IACS Contribution No. 2, UNESCO-IHP, Paris, France. $114 \mathrm{p}$.

Corte, A. E. 1976. The hydrological significance of rock glaciers. Journal of Glaciology, 17: 157-158.

Corte, A. E. 1978. Rock glaciers as permafrost bodies with debris cover as an active layer. A hydrologycal approach, Andes of Mendoza, Argentina. $1^{\circ}$ International Conference on Permafrost, Actas: 262-269, Edmonton, Canadá.

Escayola, M. P., van Staal, C. R., Davis, W. J. 2011. The age and tectonic setting of the Puncoviscana Formation in northwestern Argentina: an accretionary complex related to Early Cambrian closure of the Puncoviscana Ocean and accretion of the Arequipa-Antofalla block. Journal of South American Earth Sciences 32(4): 437-458.

Haeberli, W. 1985. Creep of mountain permafrost: internal structure and flow of alpine rock glaciers. Mitteilungen der Versuchsanstalt fürWasserbau, Hydrologie und Glaziologie, ETH, Zürich, 77: 1-142.

Haselton, K., Hilley, G. E., Strecker, M. R. 2002. Average Pleistocene climatic patterns in the southern central Andes: controls on mountain glaciation and paleoclimate implications. The Journal of Geology 110 (2): 211-226. doi: 10.1086/338414.

Horton, R. 1945. Erosional development of streams and their drainage basins hydrophysical approach to cuantitative morphology. Bulletin of the Geological Society of America. 56:275-370.

Igarzábal, A. P. 1981. El sistema glaciolítico de la Cuenca Superior del Río Juramento, Provincia de Salta. $8^{\circ}$ Congreso Geológico Argentino, Actas 4: 167-183. San Luis.

International Permafrost Association (IPA), 1994. En: ipa.arcticportal.org/publications

Köppen, W. 1923. Die Klimate der Erde. Grundiriss deer Klimakunde. Berlín und Leipzig. X+ 369 pgs. En: Mendoza y González, 2011.

Kull, C., Hanni, F., Grosjean, M. y Veit, H. 2003. Evidence of an LGM cooling in NW Argentina $\left(22^{\circ} \mathrm{S}\right)$ derived from a glacier climate model. Quaternary International, 108: 3-11.

Martini, M. A., Strelin, J. y Astini, R. 2013. Inventario y caracterización morfoclimática de los glaciares de roca en la Cordillera Oriental argentina (entre $22^{\circ}$ y $25^{\circ} \mathrm{S}$ ). Revista Mexicana de Ciencias Geológicas 30: 569-581.

Masaguer, G. 2009. Determinación e inventario de geoformas de permafrost andino en una cuenca de la Sierra de Santa Victoria. Seminario de la Carrera de Geo- 
logía para optar al título de Geólogo. Facultad de Ciencias Naturales e Instituto Miguel Lillo, Universidad Nacional de Tucumán. Inédito, 120 p.

Puchulu, M. E. y Fernández, D. S. 2017. Suelos representativos del noroeste argentino. En: Muruaga, C. M. y Grosse, P. (Eds.), Ciencias de la Tierra y Recursos Naturales del NOA. Relatorio del XX Congreso Geológico Argentino, San Miguel de Tucumán: 874-912. ISBN 978-987-42-6666-8.

Roer, I. y Nyenhuis, M. 2007. Rockglacier activity studies on a regional scale: comparison of geomorphological mapping and photogrammetric monitoring. Earth Surface Processes and Landforms: The Journal of the British Geomorphological Research Group, 32(12), 1747-1758.

Sánchez, M. Cristina y Salfity, José .1999. La cuenca cámbrica del Grupo Mesón en el noroeste argentino: desarrollo estratigráfico y paleogeográfico. Acta Geológica Hispánica, 34(2-3), 123-139.

Trombotto, D. 2000. Survey of cryogenic processes. Periglacial forms and permafrost conditions in South America. Revista do Instituto Geológico 21(1/2): 33-55.

Trombotto, D., Wainstein, P. y Arenson, L. 2014. Guía terminológica de la Geocriología Sudamericana. Terminological Guide of the South American Geocryology. Vázquez Mazzini Editores, Buenos Aires, 124 pp.

Turner, J. C. M. 1960. Estratigrafía de la sierra de Santa Victoria, provincias de Salta y Jujuy. Academia Nacional de Ciencias, Córdoba, 41, 163-196.

Van Everdingen, R. 2005. Multilanguage glossary of permafrost and related groundice terms. Boulder, Co: National Snow and Ice data center / World Data Center for Glaciology. 90 pp.

Zech, J., Zech, R., Kubik, P. W., Veit, H. 2009. Glacier and climate reconstruction at Tres Lagunas, NW Argentina, based on 10Be surface exposure dating and lake sediment analyses. Palaeogeography, Palaeoclimatology, Palaeoecology 284: 180-190, http://dx.doi.org/10.1016/j.palaeo.2009.09.023

Zipprich M., Reizner, B., Veit, H., Zech, W. and Stingl, H. 2000. Upper Quaternary landscape and climate evolution in the Sierra de Santa Victoria (northwestern Argentina) deduced from geomorphologic and pedologic evidence. Zentralblatt für Geologieund Paläontologie 7/8: 997-1012. 